\title{
EVALUATION OF THE PERFORMANCE OF
}

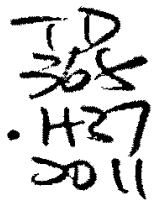

\section{MULTIPLE WATER QUALITY LOADING \\ INDEX SYSTEMS FOR SAPGYO RIVER}

by

\section{FAIZUL HASAN}

Master of Philosophy in Water Resources Engineering

University of Engineering and Technology, Lahore, Pakistan, 2001

Master of Business Administration

University of the Punjab, Lahore, Pakistan, 2001

Bachelor of Science (Engineering) in Civil Engineering

Aligarh Muslim University, Aligarh, India, 1980

\section{A project \\ presented to Ryerson University}

in partial fulfillment of the

requirements for the degree of

Master of Engineering

in the Program of

Civil Engineering

Toronto, Ontario, Canada, 2011

(C) FAIZUL HASAN, 2011 


\section{Author's Declaration}

I hereby declare that I am the sole author of this thesis or dissertation.

I authorize Ryerson University to lend this thesis or dissertation to other institutions or individuals for the purpose of scholarly research.

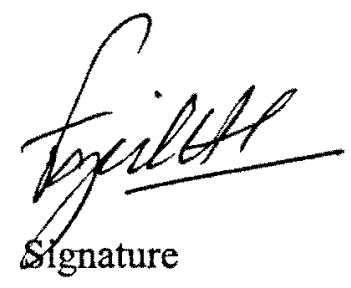

I further authorize Ryerson University to reproduce this thesis or dissertation by photocopying or by other means, in total or in part, at the request of other institutions or individuals for the purpose of scholarly research.

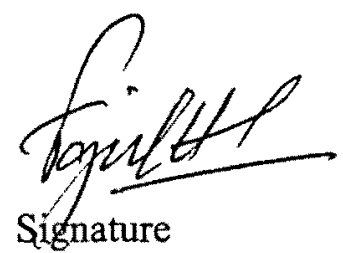




\title{
EVALUATION OF THE PERFORMANCE OF MULTIPLE WATER QUALITY LOADING INDEX SYSTEMS FOR SAPGYO RIVER
}

\author{
Master of Engineering, 2011 \\ FAIZUL HASAN \\ Civil Engineering Program \\ Ryerson University
}

\begin{abstract}
To enhance the sustainability of water-quality-management system, the modeling results of simulated pollutants are needed to translate into an understandable single unit water quality index to help the decision-makers for making relevant judgments. QUAL2E model is helpful in translating the results of simulated pollutants into a single water quality rating unit termed as "QUAL2E water quality loading index (QWQLI)". This approach is adopted to evaluate the performance of National Sanitation Foundation's Water Quality Index (NSFWQI) and Canadian Council of Ministers of the Environment's Water Quality Index (CCMEWQI) using data set of Sapgyo River. CCMEWQI results are found better, especially for meeting the desired quality objectives. Additionally, a decision-making process has been suggested based on better found QWQLI result to maintain the whole river channel at acceptable water quality standards. The study results imply that further study should be carried out using minimum four variables, each having at least four test samples to compute QWQLI using CCMEWQI approach.
\end{abstract}




\section{Acknowledgements}

The author acknowledges his indebtedness and sincere gratitude to his supervisor $\mathrm{Dr}$. $\mathrm{Li}$ He, PEng, Assistant Professor, Department of Civil Engineering, Ryerson University for his continuous guidance, assistance and inspired encouragement through the entire course of this project work.

The author is grateful to Saad Yousaf, PEng, Engineering Department, City of Vaughan for extending his cooperation in arranging the project related data/ information and providing his expert advice at time to time to complete this project.

The author is highly thankful and grateful to Dr. Jinyuan Liu, Assistant Professor, Department of Civil Engineering, Ryerson University for providing his valuable comments and suggestions in finalizing this project.

The author wishes to express his special thanks to Ammar Hasan for his partial support to complete this project. 


\section{Table of Contents}

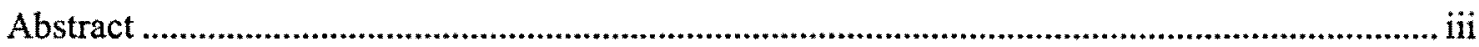

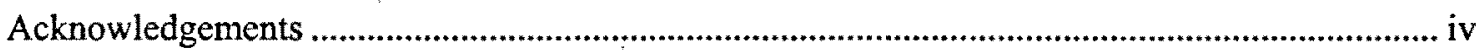

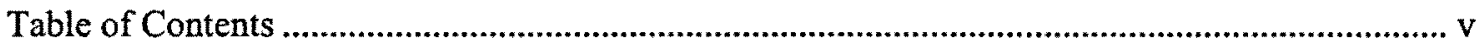

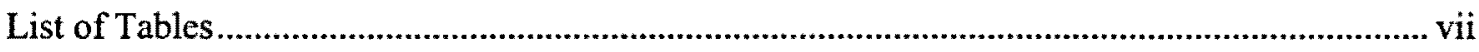

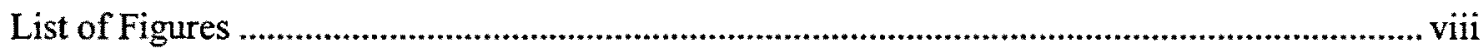

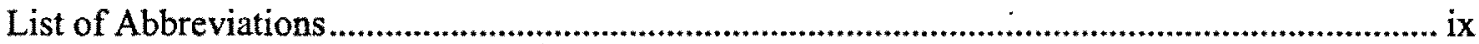

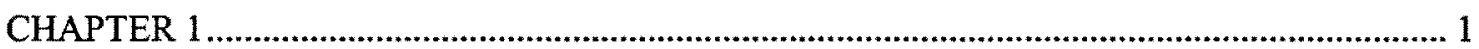

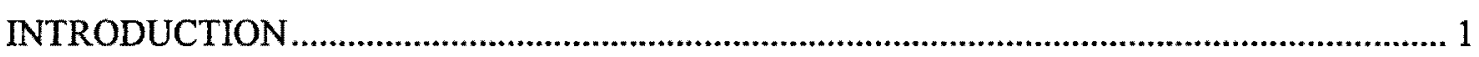

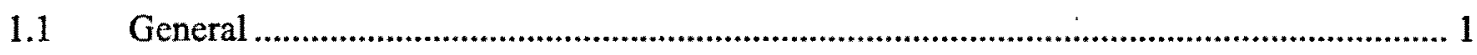

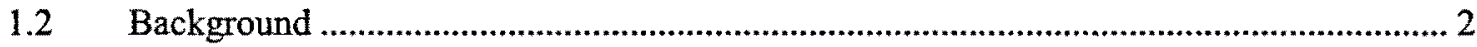

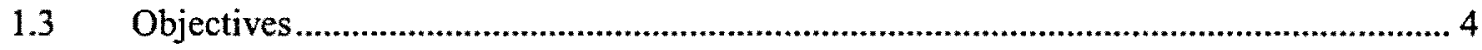

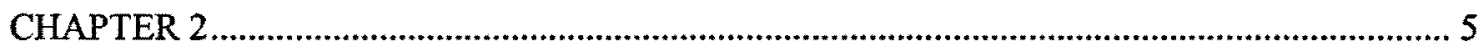

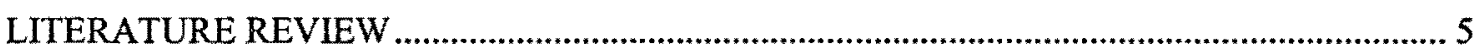

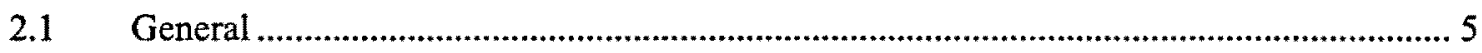

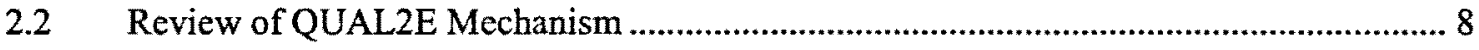

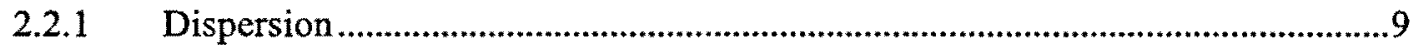

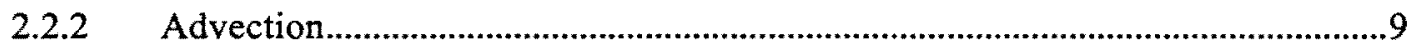

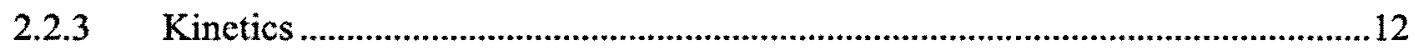

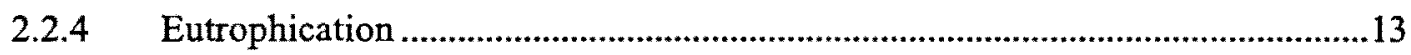

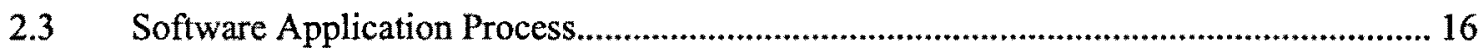

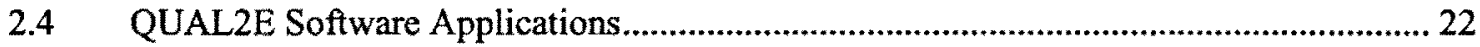

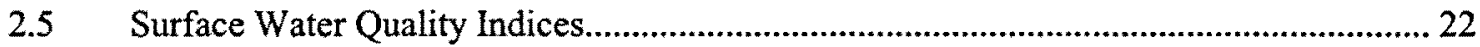

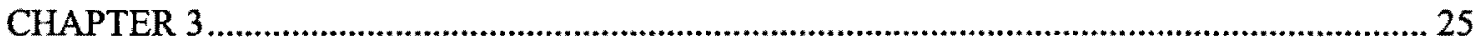

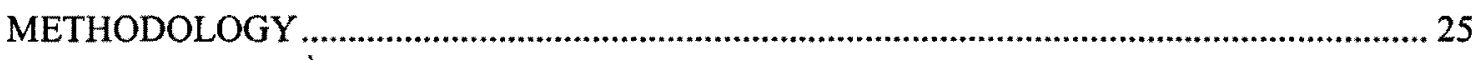

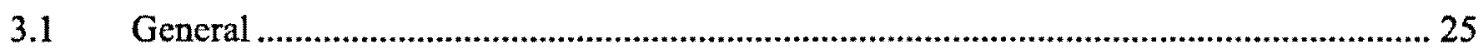

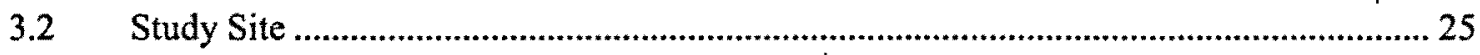

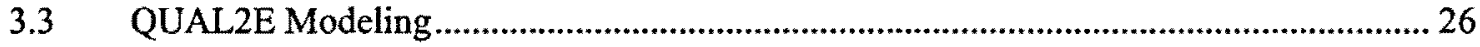

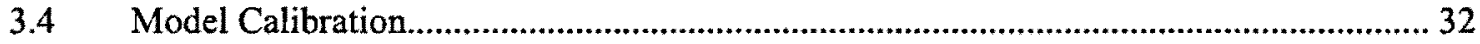

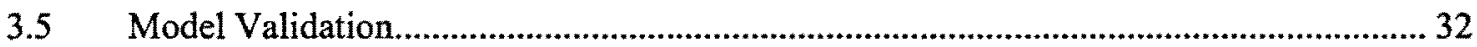


3.6 Determination of QUAL2E Water Quality Loading Index by Applying NSFWQI Approach

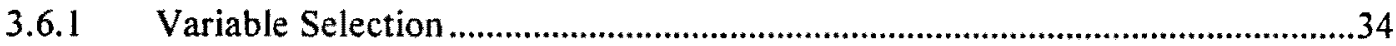

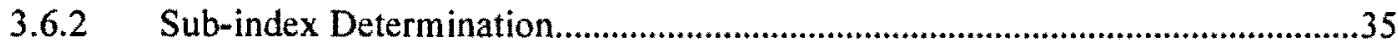

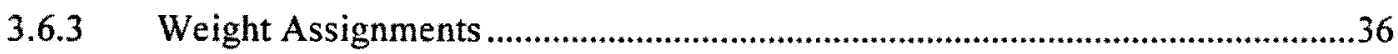

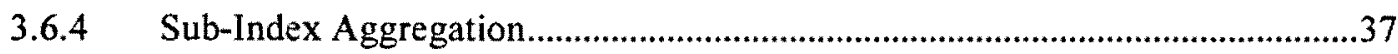

3.6.5 Computation of QWQLI with Application of NSFWQI System Approach.....38

3.7 Determination of QUAL2E Water Quality Loading Index by Applying CCMEWQI

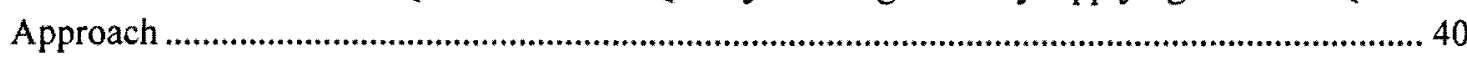

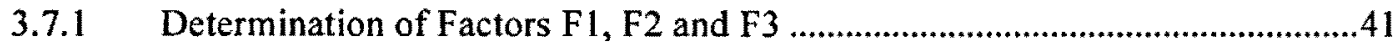

3.7.2 Determination of CCMEWQI using Factors F1, F2 and F3 .........................42

3.7.3 Computation of QWQLI with Application of CCMEWQI System Approach.44

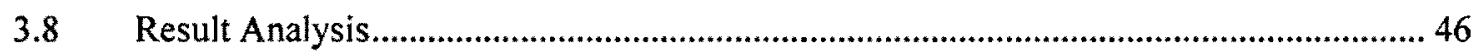

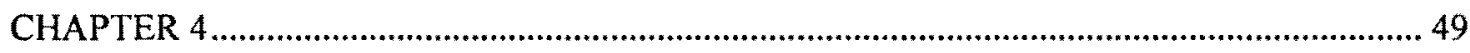

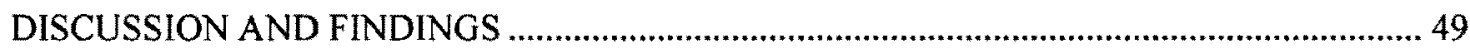

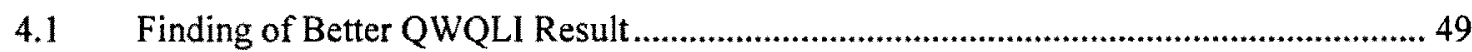

4.2 Decision-Making Process Based on Better Found QWQLI Result................................ 51

4.3 Analyzing Decision-Making Process Based on QWQLI Result of Sapgyo River ........... 55

CHAPTER 5

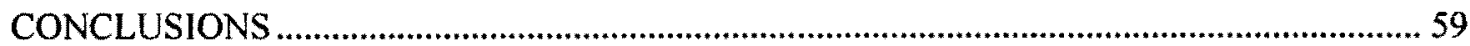

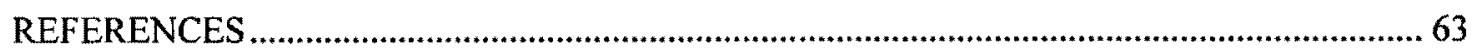




\section{List of Tables}

Table 2.1 Biochemical and physical processes of the river water quality model QUAL2 in

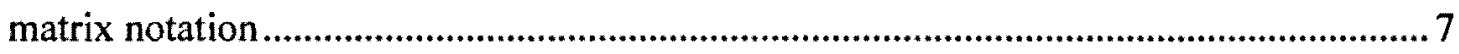

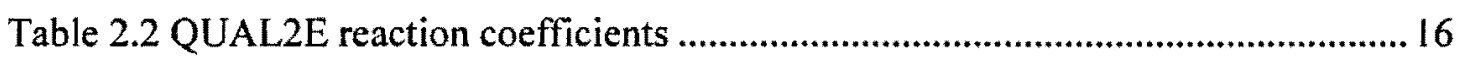

Table 2.3 Classification of water-quality indices (WQIs) ….............................................24

Table 3.1 Average concentration of the pollutants observed in $2004 \ldots \ldots \ldots \ldots \ldots \ldots \ldots \ldots \ldots \ldots . . . . .26$

Table 3.2 Element types and assigned flag numbers .........................................................29

Table 3.3 Pollutant's load of headwater and input sources before entering into WTPs.. 29

Table 3.4 QUAL2E modeling result of the Sapgyo River (2004) .....................................31

Table 3.5 Five-class standards of BOD, T-N, and T-P and their descriptors for NSFWQI

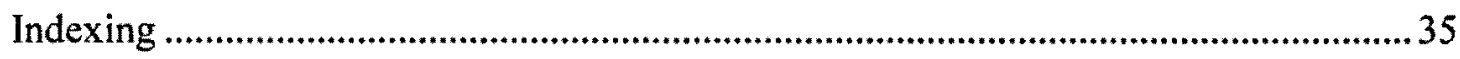

Table 3.6 Sub-index functions for QWQLI indexing .......................................................36

Table 3.7 Weight assignment for QWQLI indexing.......................................................38

Table 3.8 Calculations of QWQLI using NSFWQI system approach ..............................39

Table 3.9 CCMEWQI quality rating range, category type and quality condition ............40

Table 3.10 Maximum and minimum values of variables with desired objectives............44

Table 3.11 Calculations of QWQLI using CCMEWQI ....................................................45

Table 3.12 Comparison of NSFWQI and CCMEWQI based on different criteria ...........48

Table 4.1 Decision-making result of Sapgyo River using CCMEWQI system approach56 


\section{List of Figures}

Figure 2.1 Schematic description of the water quality model QUAL2E ..........................6

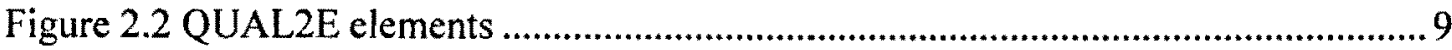

Figure 2.3 Cross-section of a trapezoidal channel showing the parameters needed to

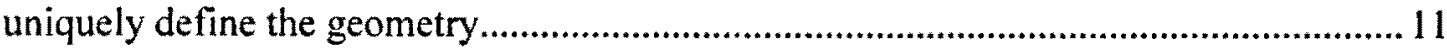

Figure 2.4 (a) River basin, and (b) QUAL2E representation as reaches and elements ... 18 Figure 2.5 (a) A stream receiving pollutant loadings from a point source and tributary (b) QUAL2E segmentation scheme conforming to the stream shown in Figure (a) .......21

Figure 3.1 Site map - location of River Sapgyo in South Korea .......................................22

Figure 3.2 QUAL2E representations as reaches and elements of Sapgyo River..............28

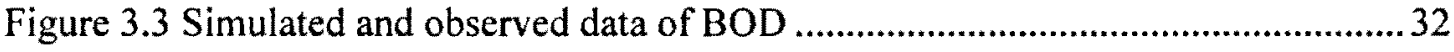

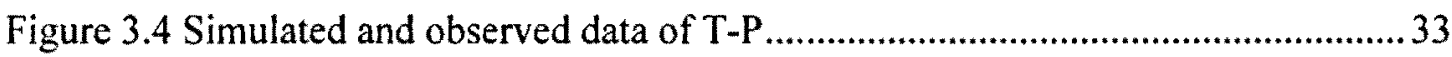

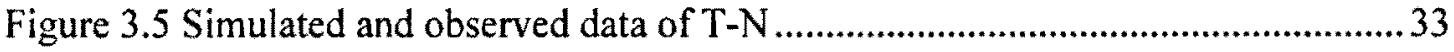

Figure 3.6 Graphical representation of the water-quality index (WQI) calculated in a three-dimensional space by summing three factors (F1, F2, and F3) as vectors

Figure 3.7 Comparison of QWQLI results using NSFWQI and CCMEWQI systems approaches

Figure 4.1 Decision-making process based on better found QWQLI result.

Figure 4.2 Comparison of QWQLI results of.Sapgyo River obtained before and after improvement

Figure 4.3 Comparison of simulated concentration of T-N before and after improvement

Figure 4.4 Comparison of simulated concentration of T-P before and after improvement 


\section{List of Abbreviations}
A
$a_{3}$
$\mathrm{ABM}$
$A_{t} R$
$b_{1}$
$b_{2}$
$b_{3}$
$b_{4}$
BOD
CBOD
CCME
CCMEWQI
Algae
Stoichiometric Coefficient
Algal Biomass
Atmospheric Re-aeration
Ammonia Oxidation Rate
Nitrite Oxidation Rate
Nitrogen Hydrolysis Rate
Phosphorous Hydrolysis Rate
Biochemical Oxygen Demand
Carbonaceous Biochemical Oxygen Demand
Canadian Council of Ministers of the Environment
Canadian Council of Ministers of the Environment's Water Quality Index
Chl-a
COD
D
DIS-P
DO
$\mathrm{DO}_{\text {sat }}$
EPA
$f(L, N, P)$
$f($ nitr)
$\mathrm{F}_{\mathrm{NH} 4}$
Ammonia Preference Factor
GA
Chlorophyll a (Algae)
Carbonaceous Oxygen Demand
Mean Stream Depth
Dissolved Phosphorous
Dissolved Oxygen
DO Saturation Concentration
Environmental Protection Agency
Algal Growth Limitation Factor
Nitrification Limitation Factor
Georgia 
Deoxygeneration Coefficient

$\mathrm{k}_{2}$

Re-aeration Coefficient

$\mathrm{k}_{3}$

BOD Settling Rate

$\mathrm{k}_{4}$

Sediment Oxygen Demand Ratio

MCDA Multi-Criteria Decision Analysis

MS

Mississippi

$\mathrm{N}$

Nitrogen

$\mathrm{NH}_{4}$

Ammonia

$\mathrm{NO}_{2}$

Nitrite

$\mathrm{NO}_{3}$

Nitrate

NPS

Non-Point Sources

nse

The Normalized Sum of Excursions

NSFWQI National Sanitation Foundation's Water Quality Index

$\mathrm{O}$

Oxygen

ORG-N

Organic Nitrogen

ORG-P

Organic Phosphorous

OWQI

Oregon Water Quality Index

$\mathrm{P}$

Phosphorous

PEC

Predicted Environmental Concentration

PNEC

Predicted No-Effect Concentration

QWQLI

QUAL2E Water Quality Loading Index

r

Algal Respiration Rate

$\mathrm{RD}$

Reduced Distance

$S_{1}$

Algal Settling Rate

$s_{2}$

Benthos Source Rate for Phosphorous 
SA

SOD

SS

$\mathrm{T}-\mathrm{N}$

T-P

USA

USACE

USEPA

UWQI

WQI

WTP
Benthos Source Rate for Nitrogen

Nitrogen Settling Rate

Phosphorous Settling Rate

South Africa

Sediment Oxygen Demand

Suspended Solids

Total Nitrogen

Total Phosphorous

United States of America

The United States Army Corps of Engineers

United States Environmental Protection Agency

Universal Water Quality Index

Water Quality Index

Water Treatment Plant 


\section{CHAPTER 1}

\section{INTRODUCTION}

\subsection{General}

Rivers and lakes are major source of surface water for providing drinking water to main cities of the states all over the world. These sources have to meet the desired water quality standards to provide safe drinking water supplies to the urban populace as well as for other water uses. Therefore, water quality of the rivers and lakes is a major concern of the municipalities for not only the public health reasons but also to protect the aquatic lives.

In many parts of the world, particularly in developing regions such as Asia, South America and Africa, the wastewater is routinely discharged directly into the surface water bodies. This is because of the fact that the world's fastest growing cities are mostly located in low income countries which are characterized by poor water infrastructures and wastewater treatment facilities. This scenario is typically associated with high levels of suspended solids (SS), biochemical oxygen demand (BOD), nitrite $\left(\mathrm{NO}_{2}\right)$, and un-ionized ammonia in receiving waters, resulting in significant ecological impairment. Most fundamentally, in absence of their removal by secondary sewage treatment process, the predicted environmental concentration (PEC) is often exceeds the predicted no-effect concentration (PNEC) (Finnegan et al., 2009). In developed countries, the growing numbers of chemical toxicants entering the environment through non-point sources (NPS) has led to increasing health concerns (Huang and Xia, 2001).

Generally, the urban wastewater of a city is discharged into the river through the point sources, whereas the same river again provides drinking water to the same city and further to the urban areas located at downstream of the river. The cycle of reuse of water from the water bodies for drinking and other uses of water is a continuous process. Therefore, wastewater is required to be treated first before discharging it into the receiving water bodies. The wastewater treatment should be based on 
producing an effluent that induced an acceptable level of water quality in the receiving waters. In order to determine the safe treatment level, it is necessary to predict water quality as a function of waste loading. Hence, to evaluate the future condition of the river water in view of actual pollution loading and to provide different management options, water quality models were introduced.

The states are required to develop water quality standards, on a site specific basis, for all of their surface waters. These should:

(i) Include provisions for restoring and maintaining the chemical, physical and biological integrity of water supplies;

(ii) Provide, where attainable, water quality for protection and propagation of fish, shellfish, and wildlife and recreation in and on the water ("fishable/ swimmable"); and

(iii) Consider the use and value of waters for public water supplies, propagation of fish and wildlife, recreation, agriculture and industrial purposes, and navigation.

The water quality standards must meet the requirements of the Clean Water Act and water standards regulations. Water quality standards are composed of useclassifications, quality criteria, and an anti-degradation policy (Viessman et al, 2009).

\subsection{Background}

Degradation of rivers at different levels has increased during the last century. Apart from chemical pollution affecting surface waters, modification of hydromorphological conditions and reduced flow can also affect biological communities in severe ways. Therefore, aquatic ecosystem requires a good environmental status to promote sustainable use of the water resource in time. In order to maintain an acceptable water quality, the water quality modeling is an ideal approach to simulate physical, chemical, and biological changes in water bodies (James, 1984). It involves the prediction of water pollution using mathematical simulation techniques. It can also be used to predict water quality in terms of the real observed data at a high frequency and over a long period of time. So far, a number of water quality models 
have been widely applied to assess water quality. These include QUAL2E (Brown and Barnwell, 1987), WASP5 (Ambrose et al., 1993), CE-QUAL-W2 (Cole and Buchak, 1995), and HEC-5Q (USACE, 1986). However, among the existing water quality models, QUAL2E, that was developed and released by USEPA (United States Environmental Protection Agency) in 1985, is one of the most popular models (Cox, 2003). It is an enhanced steady-state model used mainly to simulate the inflow and water quality of rivers and streams.

Unlike water quantity, which can be expressed in precise terms, water quality is a multi-parameter attribute. The utility of a water quality index (WQI) relies in the aggregation of information about water-quality parameters at different times and in different places and translating this information into a single score that represents the time period and the spatial unit under consideration. In this way, a WQI becomes an easy communication tool for transmitting scientific information from experts to the decision-makers and general public audience.

In general, water quality indices incorporate data from multiple water quality parameters into a mathematical equation that rates the health of a stream with a single number. This number is placed on a relative scale that rates the water quality in categories ranging from very bad to excellent (lowa Watershed Monitoring and . Assessment Program, 2006). There are several water quality indices that have been developed to evaluate water quality in United States and in Canada. All of these indices have eight or more water quality variables (Said et al., 2004).

This study describes the utility of QUAL2E as a modeling package in the evaluation of water quality improvement of a river. A case study of the Sapgyo River of South Korea has been discussed to determine the pollutant loads using QUAL2E software. The data set of the simulated pollutants, that mainly describe the river water quality, has been used to determine the water quality rating in a single unit for use of the decision-makers and general public audience. A single score QUAL2E water quality loading index (QWQLI) has been determined using two different water quality index systems of National Sanitation Foundation's Water Quality Index (NSFWQI) and 
Canadian Council of Ministers of the Environment's Water Quality Index (CCMEWQI) to compare the results. Finally, a decision-making process has been suggested on the basis of better found QWQLI result.

\subsection{Objectives}

The main objectives of the study are:

(i) To determine the pollutant loadings simulated by QUAL2E model to evaluate the water quality of Sapgyo River;

(ii) To determine QUAL2E water quality loading index (QWQLI) by applying two different water quality index systems approaches of NSFWQI and CCMEWQI using same pollutant data set of the river simulated by QUAL2E model;

(iii) To discuss and compare the QWQLI results obtained by using NSFWQI and CCMEWQI systems approaches to find the better result; and

(iv) To suggest a decision-making process on the basis of better found QWQLI result. 


\section{CHAPTER 2 \\ LITERATURE REVIEW}

\subsection{General}

The changes in the constituent concentrations in a river are due to biological, chemical, biochemical, and physical conversion processes. The historical development of Oxygen, Nitrogen, and Phosphorous models shows step-by-step extensions and increasing complexity as explained below:

(i) The starting pioneer model was introduced by Streeter and Phelps in 1925 as "Streeter-Phelps Model" describing the increase and following decrease of the oxygen deficit at downstream of a source of organic material (Streeter and Phelps, 1925);

(ii) The first version as "QUAL-I Model" was developed by F.D. Masch and Associates and the Texas Water Development Board in 1970 using old punch cards technology as its input media;

(iii) The QUAL-I Model was extended and modified as "QUAL-II Model" by Water Resources Engineers Inc. (now Camp Dresser and McKee) under contract with the U.S. Environmental Protection Agency (EPA) in 1972; and

(iv) Finally, phosphorus cycling and algae were added and model was upgraded as "Enhanced QUAL-II model" by Brown and Barnwell in 1987, which is generally written in short as QUAL2E Model.

QUAL2E is capable of simulating up to the following 15 water quality constituents in dendritic streams that are well mixed laterally and vertically (Chapra, 2008):

(i) Dissolved Oxygen (DO)

(ii) Biochemical Oxygen Demand (BOD)

(iii) Temperature

(iv) Algae as Chlorophyll a

(v) Organic Nitrogen as $\mathrm{N}$

(vi) Ammonia as $\mathrm{N}$ 
(vii) Nitrite as $\mathrm{N}$

(viii) Nitrate as $\mathrm{N}$

(ix) Organic Phosphorous as $\mathbf{P}$

(x) Dissolved Phosphorous as $\mathrm{P}$

(xi) Coliform Bacteria

(xii) Arbitrary Non-Conservative Constituents

(xiii) Conservative Constituent Type I

(xiv) Conservative Constituent Type II

(xv) Conservative Constituent Type III

It allows for multiple waste discharges, withdrawals, tributary flows, and incremental inflows and outflows. It is a versatile software package used for regulatory and policy decisions making.

Several versions of the QUAL2E model are available depending on the purpose of the use such as research, regulation, etc. Figure 2.1 shows the schematic description of processes included in QUAL2E model.

$\begin{array}{ll}\mathrm{A}_{1} \mathrm{R} & \text { Atmospheric reaeration } \\ \mathrm{DO} & \text { Dissolved oxygen } \\ \mathrm{BOD} & \text { Biochemical oxygen demand } \\ \mathrm{SOD} & \text { Sediment oxygen demand } \\ \mathrm{NH}_{4} & \text { Ammonia } \\ \mathrm{NO}_{2} & \text { Nitrite } \\ \mathrm{NO}_{3} & \text { Nitrate } \\ \text { ORG-N } & \text { Organic Nitrogen } \\ \text { CHL-a } & \text { Chlorophyll a (Algae) } \\ \text { ORG-P } & \text { Organic Phosphorous } \\ \text { DIS-P } & \text { Dissolved Phosphorous }\end{array}$

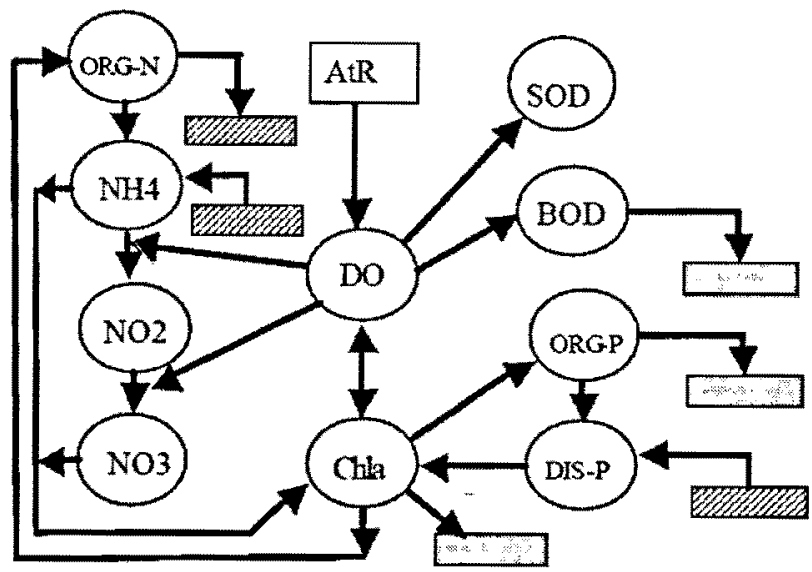

Figure 2.1 Schematic description of the water quality model QUAL2E Source: Rauch et al., 1998

The QUAL2E model includes degradation of organic material, growth and respiration of algae, nitrification (considering nitrite as an intermediate product), hydrolysis of organic nitrogen and phosphorus, reaeration, sedimentation of algae, organic phosphorus and organic nitrogen, sediment uptake of oxygen, and sediment release of nitrogen and phosphorus. All these processes consider the effect on 
oxygen, nitrogen and phosphorus cycles. The process formulations are given in Table 2.1 in matrix notation as introduced by Henze et al., 1987 (Rauch et al, 1998).

Table 2.1 Biochemical and physical processes of the river water quality model QUAL2 in matrix notation

\begin{tabular}{|c|c|c|c|c|c|c|c|c|c|c|c|}
\hline & Component & 1 & 2 & 3 & 4 & 5 & 16 & 7 & 8 & 9 & Process rate \\
\hline & Process & DO & BOD & ABM & ORG-N & $\mathrm{NH}_{4}$ & $\mathrm{NO}_{2}$ & $\mathrm{NO}_{3}$ & ORG-P & DIS-P & {$\left[\mathbf{M L}^{-3} \mathbf{T}^{-1}\right]$} \\
\hline 1 & Reaeration & 1 & & & & & & & & & $\mathrm{~K} 2 .\left(\mathrm{DO}_{3 x \mathrm{~s}}-\mathrm{DO}\right)$ \\
\hline 2 & Biodegradation & -1 & -1 & & & & & & & & $\mathrm{~K} 1 . \mathrm{BOD}$ \\
\hline 3 & BOD sedimentation & & -1 & & & & & & & & K3.BOD \\
\hline 4 & Sediment DO demand & -1 & & & & & & & & & $\mathrm{~K} 4 / \mathrm{d}$ \\
\hline 5 & Photosynthesis & a3 & & 1 & & $0.07 . F_{\mathrm{NH}}$ & & $\begin{array}{l}-0.07 \\
\left(1-F_{\mathrm{NH} 4}\right)\end{array}$ & & -0.01 & $\begin{array}{l}\mu \max . A B M \\
f(L, N, P)\end{array}$ \\
\hline 6 & Respiration & $-\mathrm{a} 4$ & & -1 & 0.07 & & & & 0.01 & & p.ABM \\
\hline 7 & Algae sedimentation & & & -1 & & & & & & & $\sigma l / \mathrm{d} . \mathrm{ABM}$ \\
\hline 8 & Nitrogen Hydrolysis & & & & -1 & 1 & & & & & B3.ORG-N \\
\hline 9 & Nitrification ${ }^{\text {1st }}$ step & -3.43 & & & & -1 & 1 & & & & B1.NH4.f(nitr) \\
\hline 10 & Nitrification $2^{\text {nd }}$ step & -1.14 & & & & & -1 & 1 & & & B2.NO2.f(nitr) \\
\hline 11 & N sedimentation & & & & -1 & & & & & & 64.NH4 \\
\hline 12 & N sediment release & & & & & 1 & & & & & $\sigma 3 / \mathrm{d}$ \\
\hline 13 & P hydrolysis & & & & & & & & -1 & 1 & B4.ORG-P \\
\hline 14 & P sedimentation & & & & & & & & -1 & & 65.ORG-P \\
\hline 15 & P sediment release & & & & & & & & & 1 & $\sigma 2 / \mathrm{d}$ \\
\hline
\end{tabular}

Source: Rauch et al., 1998

Where,

$\mathrm{DO}=$ dissolved oxygen $\left[\mathrm{ML}^{-3}\right]$

$\mathrm{DO}_{\text {sat }}=\mathrm{DO}$ saturation concentration $\left[\mathrm{ML}^{-3}\right]$;

BOD $=$ biochemical oxygen demand of organic material $\left[\mathrm{ML}^{-3}\right]$

$\mathrm{ABM}=$ algal biomass $\left[\mathrm{ML}^{-3}\right]$;

ORG-N = organic nitrogen $\left[\mathrm{ML}^{-3}\right]$;

$\mathrm{NH}_{4}=$ ammonia- $\mathrm{N}\left[\mathrm{ML}^{-3}\right]$;

$\mathrm{NO}_{2}=$ nitrite- $\mathrm{N}\left[\mathrm{ML}^{-3}\right]$

$\mathrm{NO}_{3}=$ nitrate- $\mathrm{N}\left[\mathrm{ML}^{-3}\right]$;

ORG-P = organic phosphorus $\left[\mathrm{ML}^{-3}\right]$;

DIS-P = dissolved phosphorus $\left[\mathrm{ML}^{-3}\right]$;

$\mathrm{K}_{1}=$ deoxygenation coefficient $\left[\mathrm{T}^{-1}\right]$;

$\mathrm{K}_{2}=$ reaeration coefficient $\left[\mathrm{T}^{-1}\right]$;

$\mathrm{K}_{3}=\mathrm{BOD}$ settling rate $\left[\mathrm{T}^{-1}\right]$;

$\mathrm{K}_{4}=$ sediment oxygen demand rate $\left[\mathrm{ML}^{-2} \mathrm{~T}^{-1}\right] ; \quad \mathrm{FNH}_{4}=$ ammonia preference factor.

$\mathrm{d}=$ mean stream depth $[\mathrm{L}]$;

$\mu_{\max }=$ maximum algal growth rate $\left[\mathrm{T}^{-1}\right]$;

$\mathrm{r}=$ algal respiration rate $\left[\mathrm{T}^{-1}\right]$;

$\mathrm{s}_{1}=$ algal settling rate $\left[\mathrm{LT}^{-1}\right]$;

$\mathrm{s}_{2}=$ benthos source rate for $\mathrm{P}\left[\mathrm{ML}^{-2} \mathrm{~T}^{-1}\right]$;

$s_{3}=$ benthos source rate for $\mathrm{N}\left[\mathrm{ML}^{-2} \mathrm{~T}^{-1}\right]$;

$\mathrm{s}_{4}=\mathrm{N}$ settling rate $\left[\mathrm{T}^{-1}\right]$;

$\mathrm{s}_{5}=\mathrm{P}$ settling rate $\left[\mathrm{T}^{-1}\right] ;$

$\mathrm{b}_{1}=$ ammonia oxidation rate $\left[\mathrm{T}^{-1}\right]$;

$\mathrm{b}_{2}=$ nitrite oxidation rate $\left[\mathrm{T}^{-1}\right]$;

$\mathrm{b}_{3}=\mathrm{N}$ hydrolysis rate $\left[\mathrm{T}^{-1}\right]$;

$\mathrm{b}_{4}=\mathrm{P}$ hydrolysis rate $\left[\mathrm{T}^{-1}\right]$;

$\mathrm{a}_{3}=$ stoichiometric coefficient gO/gABM [-];

$\mathrm{f}(\mathrm{L}, \mathrm{N}, \mathrm{P})=$ algal growth limitation factor;

$f($ nitr $)=$ nitrification limitation factor; and 


\subsection{Review of QUAL2E Mechanism}

A mass balance is used to keep track of the water quality constituents and both advective and dispersion modes of transport are considered in mass balance equation which can be written generally as:

$$
V \frac{\partial c}{\partial t}=\frac{\partial\left(A_{c} E \frac{\partial c}{\partial x}\right)}{\partial x} d x-\frac{\partial\left(A_{c} U c\right)}{\partial x} d x+V \frac{d c}{d t}+\mathrm{s}
$$

Accumulation

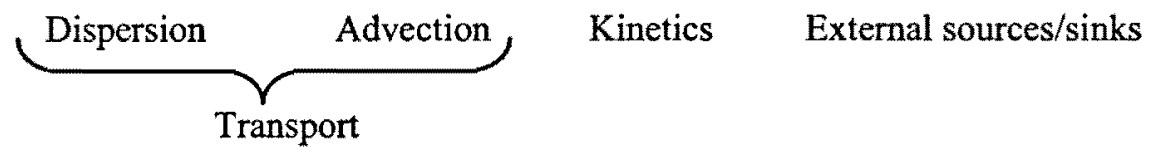

Where, $\quad \mathrm{V}=$ volume

$\mathrm{C}=$ constituent concentration

$\mathrm{A}_{\mathrm{c}}=$ element cross-sectional area

$\mathrm{E}=$ longitudinal dispersion coefficient

$\mathrm{X}=$ distance

$\mathrm{U}=$ average velocity

$\mathrm{S}=$ external source (positive) or sinks (negative) of the constituent

The advection specifies the movement of the constituents with water as it flows to downstream. The dispersion relates to the spreading of the constituents that occurs primarily due to shear force. In order to limit the discussion under this project, only two constituents carbonaceous biochemical oxygen demand (CBOD) and dissolved oxygen (DO) have been discussed under the kinetics.

As the software moved to time-sharing systems with rapid evolution of personal computers, a user-friendly interface for entering the input file and viewing the results of QUAL2E simulation has been developed. The present version QUAL2E is currently maintained by the EPA's center for water quality modeling in Athens, Georgia (Chapra; 2008). 


\subsubsection{Dispersion}

In order to compute dispersion as a function of the channel's characteristics, QUAL2E model uses the following relations:

$$
\mathrm{E}=3.11 \mathrm{KnUH}^{5 / 6}
$$

Where, $\quad \mathrm{E}=$ longitudinal dispersion coefficient $\left(\mathrm{m}^{2} \mathrm{~s}^{-1}\right)$

$n \quad=$ channel's roughness coefficient (dimensionless)

$\mathrm{U} \quad=$ mean velocity (mps)

$\mathrm{H} \quad=$ mean depth $(\mathrm{m})$

$\mathrm{K}=$ a dispersion parameter (dimensionless)

$\mathrm{K}$ is defined as:

$$
\mathrm{K}=\frac{E}{H U^{*}}
$$

Where, $\quad \mathrm{U}^{*} \quad=$ shear velocity $\left(\mathrm{ms}^{-1}\right)$

Once $\mathrm{K}$ is established, it provides a formula to compute dispersion as a function of non-uniform flow conditions. It is in this way that $\mathrm{K}$ is used in QUAL2E.

\subsubsection{Advection}

The assumptions of QUAL2E model are steady and non-uniform flow. Steady flow does not vary temporarily and non-uniform flow implies that it varies spatially. A general representation of the QUAL2E element scheme is shown in Figure 2.2.

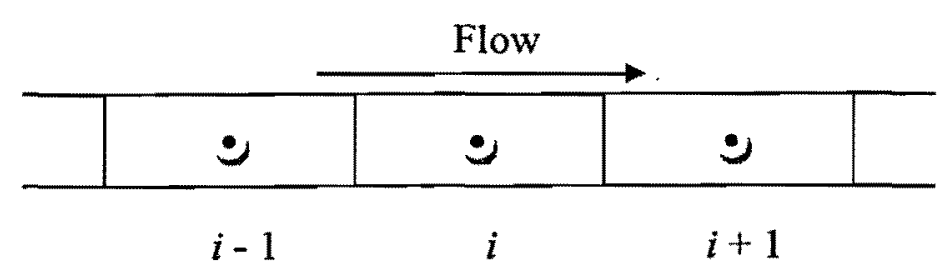

Figure 2.2 QUAL2E elements 
Under the steady and non-uniform flow conditions, the flow balance for an element $i$ can be written as:

$$
\mathrm{Q}_{i-1} \pm \mathrm{Q}_{x, i}-\mathrm{Q}_{i}=0
$$

Where, $\quad Q_{i-1}=$ flow from the upstream element

$\mathrm{Q}_{i} \quad=$ outflow from the element

$\mathrm{Q}_{x, i}=$ lateral flow into (positive) or out of (negative) the element

After establishment of flow balance, it is necessary to determine the other hydrogeometric characteristics for each element, particularly the resulting water velocity, depth, and cross-sectional area. This relationship of other hydrogeometric characteristics can be made by using power equations and manning equation.

\section{Power Equations}

The relationship of mean velocity and depth to flow can be written as:

$$
\begin{aligned}
& \mathrm{U}=a Q^{b} \\
& \mathrm{H}=\alpha \mathrm{Q}^{\beta}
\end{aligned}
$$

Where, $\quad \mathrm{H}=$ mean depth

$\mathrm{U}=$ mean velocity

$\mathrm{Q}=$ discharge

a, b, $\alpha$ and $\beta=$ empirical constants, to be determined from stage-discharge rating curves.

Once the velocity has been determined, cross-sectional area $\left(A_{c}\right)$ can be calculated by using the following continuity equation:

$$
\mathrm{A}_{\mathrm{c}}=\mathrm{Q} / \mathrm{U}
$$




\section{Manning Equation}

Manning equation gives the relation of channel characteristics and flow. In metric units, the manning equation can be written as:

$$
\mathrm{Q}=\frac{1}{n}\left[\mathrm{~A}_{\mathrm{c}} \mathrm{R}^{2 / 3} \mathrm{~S}_{\mathrm{e}}^{1 / 2}\right]
$$

Where, $\quad Q=$ channel's flow $\left(\mathrm{m}^{3} \mathrm{~s}^{-1}\right)$

$\mathrm{n}=$ Manning's roughness coefficient

$A_{c}=$ channel's cross-sectional area $\left(\mathrm{m}^{2}\right)$

$\mathrm{R}=$ channel's hydraulic radius $(\mathrm{m})$

$S_{e}=$ slope of the channel's energy grade line (dimensionless).

It is assumed that flow is steady, cross sections are constant, and the energy slope is equal to the channel slope. The QUAL2E model also assumes that the channel has a trapezoidal cross-section as shown in Figure 2.3.

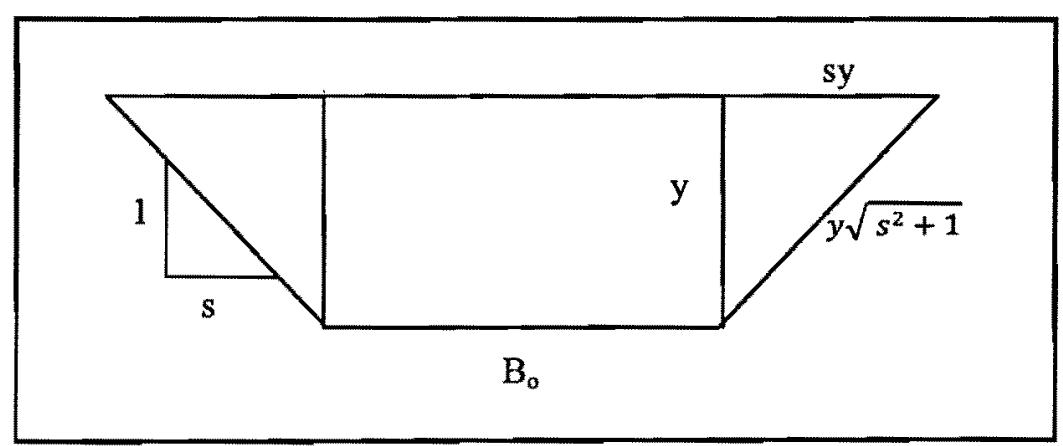

Figure 2.3 Cross-section of a trapezoidal channel showing the parameters needed to uniquely define the geometry

The cross-sectional area and hydraulic radius can be expressed as a function of depth as calculated below:

Let the bottom width of channel $=B_{0}$,

Side slope of the channel $\quad=1$ vertical to $s$ horizontal (both side slopes are same)

Depth of water flow in channel $=\mathrm{y}$

Then, each trapezoidal side $\quad=\sqrt{y^{2}+s^{2} y^{2}}$

$$
=y \sqrt{s^{2}+1}
$$


Top width of water surface

$$
\begin{aligned}
& =B_{o}+2 s y \\
& =\left[\frac{B_{o}+\left(B_{o}+2 s y\right)}{2}\right] \\
& =\left(B_{o}+s y\right) y
\end{aligned}
$$

Therefore, cross-sectional area $A_{c}=\left[\frac{B_{0}+\left(B_{0}+2 s y\right)}{2}\right] y$

Wetted perimeter $(\mathrm{P})$

$$
=2\left(y \sqrt{1+s^{2}}\right)+B_{o}
$$

Channel hydraulic radius $(\mathrm{R}) \quad=\frac{A_{c}}{P}$

$$
=\frac{\left(B_{0}+s y\right) y}{B_{0}+2 y \sqrt{1+s^{2}}}
$$

Now, if $Q$ is given, the manning equation Eq. (2.8) becomes nonlinear equation that can be numerically solved for depth. With the help of this calculated constant depth along the river, area can be determined to compute velocity.

\subsubsection{Kinetics}

The kinetics for carbonaceous biochemical oxygen demand (CBOD) and dissolved oxygen (DO) constituents can be represented mathematically by the following equations:

$$
\frac{d L}{d t}=-K_{1} L-K_{3} L
$$

and

$$
\frac{d o}{d t}=K_{2}\left(o_{s}-o\right)-K_{1} L-\left(K_{4} / H\right)
$$

Where, $\quad \mathrm{L}=$ carbonaceous BOD $\left(\mathrm{mg} \mathrm{L}^{-1}\right)$

$\mathrm{K}_{1}=\mathrm{BOD}$ decomposition rate $\left(\mathrm{d}^{-1}\right)$

$\mathrm{K}_{3}=\mathrm{BOD}$ setting rate $\left(\mathrm{d}^{-1}\right)$

$\mathrm{o}=$ dissolved oxygen concentration $\left(\mathrm{mg} \mathrm{L}^{-1}\right)$

$\mathrm{K}_{2}=$ reaeration rate $\left(\mathrm{d}^{-1}\right)$

$\mathrm{o}_{\mathrm{s}}=$ dissolved oxygen saturation concentration $\left(\mathrm{mg} \mathrm{L}^{-1}\right)$

$\mathrm{K}_{4}=$ sediment oxygen demand $\left(\mathrm{g} \mathrm{m}^{-2} \mathrm{~d}^{-1}\right)$ 
It is important to note that all the rates (the K's) are corrected for temperature by the following equation:

$$
\mathrm{K}=\mathrm{K}_{20} \theta^{\mathrm{T}-20}
$$

Where, $\quad \mathrm{K}=$ rate at temperature $\mathrm{T}$

$\mathrm{K}_{20}=$ rate at $20^{\circ} \mathrm{C}$

$\theta=$ temperature correction factor

All the rates in Eq. (2.12) and Eq. (2.13) can be entered directly to QUAL2E software.

\subsubsection{Eutrophication}

QUAL2E Model can be used to simulate both temperature and nutrient/ algae dynamics in the flowing waters.

\section{Temperature}

Using the same pattern of mass balance equation (2.1), a heat balance equation can be written as:

$$
\frac{\partial T}{\partial t} \quad=\frac{\partial\left(A_{x} E \frac{\partial T}{\partial x}\right)}{A_{x} \partial x} d x-\frac{\partial\left(A_{x} U T\right)}{A_{x} \partial x} d x+\frac{s}{p C V}
$$

In this equation, the source term $\mathrm{dT} / \mathrm{dt}$ is omitted because the internal heat generation or loss (such as viscous dissipation of energy and boundary friction etc.) is negligible. In addition, it is also assumed that the transfer of heat between the bottom sediments and the stream is ignored because it is usually negligible. Therefore, the external sources and sinks of heat are purely dependent on transfer across the airwater interface, which can be presented as:

$$
\begin{aligned}
& \mathrm{S}=\mathrm{H}_{\mathrm{sn}}+\mathrm{H}_{\mathrm{an}}-\left(\mathrm{H}_{\mathrm{br}}+\mathrm{H}_{\mathrm{c}}+\mathrm{H}_{\mathrm{e}}\right) \\
& \text { net absorbed radiation water-dependent terms }
\end{aligned}
$$

Where, $\quad \mathrm{H}_{\mathrm{sD}}=$ net solar shortwave radiation

$\mathrm{H}_{\mathrm{an}}=$ net atmospheric long wave radiation

$\mathrm{H}_{\mathrm{br}}=$ long wave back radiation from the water

$\mathrm{H}_{\mathrm{c}}=$ conduction

$\mathrm{H}_{\mathrm{e}}=$ evaporation 
Solar radiation is internally calculated on the basis of parameters such as latitude and time of year. This is really a nice feature of the model since it obviates the need for the user to obtain such information independently. Equation (2.16) can be substituted into equation (2.15) to calculate the final heat balance.

\section{Nutrients and Algae}

QUAL2E model simulates the kinetics of the nutrients including nitrogen and phosphorus. It also calculates the impact of these nutrients on plant biomass. The addition of these constituents has the following two effects on oxygen:

(i) Conversion of ammonia to nitrate uses oxygen in the nitrification process; and

(ii) Nitrogen and phosphorous can induce plant growth.

The resulting photosynthesis and respiration of the plant can add and deplete oxygen from the stream. The QUAL2E kinetics for the nutrient/plant components can be written as provided below:

Algae (A)

$$
\frac{d A}{d t} \quad=\mu A-\rho A \quad-\frac{\sigma_{1}}{H} A
$$

Accumulation Growth Respiration Settling

\section{Organic Nitrogen $\left(\mathbf{N}_{4}\right)$}

$$
\frac{d N_{4}}{d t}=\alpha_{1} \rho A \quad-3 \beta_{3} N_{4}-\sigma_{4} N_{4}
$$

Accumulation Respiration Hydrolysis Settling

\section{Ammonia Nitrogen $\left(\mathrm{N}_{1}\right)$}

$\frac{d N_{1}}{d t}=\beta_{3} N_{4}-\beta_{1} N_{1}+\frac{\sigma_{3}}{H}-\alpha_{1} \mu A$

Accumulation Hydrolysis Nitrification Sediment Growth 
Nitrite Nitrogen $\left(\mathrm{N}_{2}\right)$

$\frac{d N_{2}}{d t}=\beta_{1} N_{1}-\beta_{2} N_{2}$

Accumulation Nitrification Nitrification

Nitrate Nitrogen $\left(\mathrm{N}_{3}\right)$

$\frac{d N_{3}}{d t}=\beta_{2} N_{2}-(1-F) \alpha_{1} \mu A$

Accumulation Nitrification Growth

Organic Phosphorus $\left(\mathbf{P}_{1}\right)$

$\frac{d P_{1}}{d t} \quad=\quad \alpha_{2} \rho A-\beta_{4} P_{1}-\sigma_{5} P_{1}$

Accumulation Respiration Decay Settling

Inorganic Phosphorus $\left(\mathrm{P}_{2}\right)$

$\frac{d P_{2}}{d t}=\beta_{4} P_{1}+\frac{\sigma_{2}}{H}-\alpha_{2} \mu A$

Accumulation Decay Sediment Growth

Carbonaceous Biochemical Oxygen Demand (L)

$\frac{d L}{d t} \quad=-K_{1} L-K_{3} L$

Accumulation Decay Settling

Dissolved Oxygen (DO)

$\frac{d o}{d t}=K_{2}\left(O_{s}-O\right)-K_{1} L-\frac{K_{4}}{H}$

Accumulation Reaeration Decomposition SOD

$+\left(\alpha_{3} \mu-\alpha_{4} \rho\right) A-\alpha_{5} \beta_{1} N_{1}-\alpha_{6} \beta_{2} N_{2}$

Growth Respiration Nitrification 
It may be noted that the nitrogen, phosphorous, and kinetic constituents can be simulated without computing oxygen and CBOD. However, if they are computed, the oxygen kinetics is modified to account for the effects of nitrification and plant growth/respiration.

\subsection{Software Application Process}

The QUAL2E model has been employed to determine the profiles of dissolved oxygen (DO), biochemical oxygen demand (BOD), total nitrogen (T-N), and total phosphorous (T-P) parameters which are frequently used to establish water quality along the river extension.

In a natural aquatic medium, the concept of BOD loading is intimately related to DO concentration. BOD is the use of DO in the water body by micro-organisms to decompose the organic substrate and to oxidize the nitrogen and mineral species contained in an effluent. Also, the term BOD can be applied to the substrate itself. The predominant chemical reaction may be generally given as:

Organic substrate $+\mathrm{O}_{2} \stackrel{\text { micro-organisms }}{\longrightarrow} \mathrm{CO}_{2}+\mathrm{H}_{2} \mathrm{O}+$ new cells

The hydraulic coefficients required by the model are determined by regression of the hydraulic parameters: velocity, depth, and flow rate. The longitudinal dispersion coefficient is evaluated based on the physical analysis of each reach. The reaction coefficients are determined from values indicated in literature. The QUAL2E manual defines the ranges of each reaction coefficient as provided in Table 2.2 (Brown and Barnwell, 1987). All coefficients are temperature-dependent. As applied, the model considers only the reaction coefficients corresponding to the DO and BOD.

Table 2.2 QUAL2E reaction coefficients

\begin{tabular}{|l|l|l|}
\hline Coefficient & Definition & Range \\
\hline$k_{1}\left(\right.$ day $\left.^{-1}\right)$ & BOD decay (oxygen demand) & 0.02 to 3.4 \\
\hline$k_{2}\left(\right.$ day $\left.^{-1}\right)$ & Reaeration & 0 to 100 \\
\hline$k_{3}\left(\right.$ day $\left.^{-1}\right)$ & BOD decay by sedimentation & -0.36 to 0.36 \\
\hline$k_{4}\left(\mathrm{mgO}_{2} / \mathrm{ft}^{2}\right.$ day) & SOD decay (benthic oxygen demand) & Variable \\
\hline
\end{tabular}

Source: Brown and Barnwell, 1987 
The QUAL2E model numerically solves the system of differential equations involving pollutants by finite differences using the input data. The solution takes into account the interaction between the variables, effect of reaeration on BOD decay, influence of the sediment on DO consumption and BOD decay, and the pollutants dilution/concentration effects due to entrance and exit of loads into and from the river. Also, the hydraulic dynamics is considered, especially with regard to longitudinal dispersion, and it is described by a coefficient in the dispersive term of the transport equation.

As shown in Figure 2.4 (a), a river basin consists of the main river and its tributary. The model divides the stream into a network of headworks, reaches and junctions. The most functional network part is the reaches for which input data is provided as physical, chemical and biological parameters and coefficients. Each reach is assumed to have the homogeneous hydrogeometric properties. Each reach is further divided into a number of small computational elements which are also called control volumes as shown in Figure 2.4 (b). The hydrological balance is maintained through flow, heat balance through temperature, and material balance through concentration for these elements. 


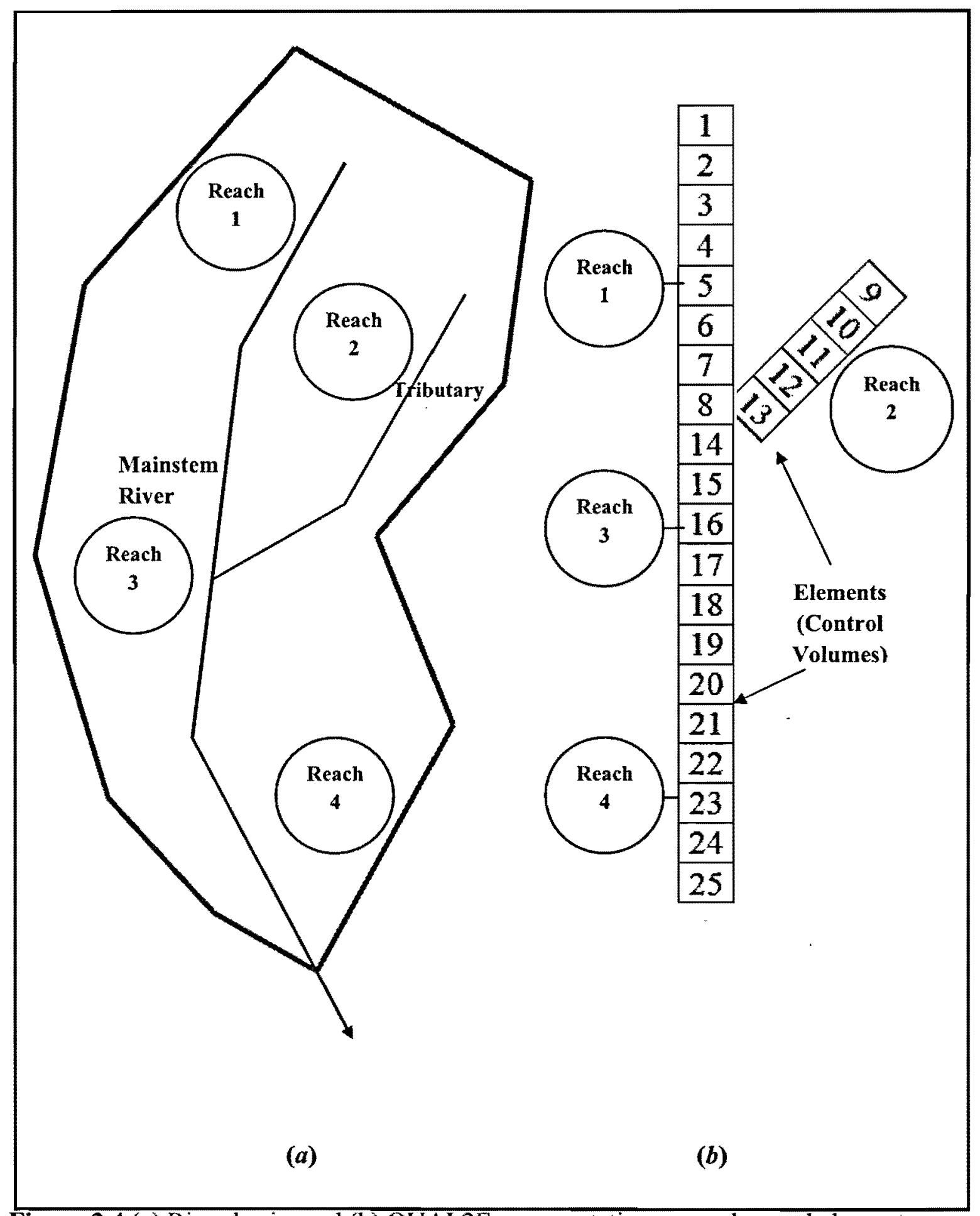

Figure 2.4 (a) River basin, and (b) QUAL2E representation as reaches and elements 
The model application process involves the following four steps:

\section{First Step}

Develop the spatial segmentation scheme for the river system to be modeled. For segmentation of the river, the system is divided into reaches of constant hydrogeometric characteristics. The name for each reach is given by the users. Generally, either each reach has its already given common name or it is denoted according to its actual reduced distance ( $\mathrm{RD}$ ) falling on the river. The first reach is generally called MS-Head. The abbreviation 'MS' is used to designate that we are simulating a 'Main Stem' of a river with no tributaries modeled explicitly. These reaches are given their serial number starting from head towards end reach. In this way, every reach is assigned its name and serial number.

\section{Second Step}

The reaches are further divided into equal length of computational elements which are also called control volumes. Each element must be given its serial number in order from the headwater reach to the most downstream point in the system.

\section{Third Step}

Each element is designated with its relevant type. Each element type is given a particular number. The elements are of seven types as given below:

\section{Element Type}

Headwater element

Standard element

Element just upstream from a junction

Junction element

Last element in system

Input element

Withdrawal element

\section{Element Type Number}

1

2

3

4

5

6

7

In order to clearly understand the process, the above steps can be explained through a general example of a stream. As shown in Figure 2.5 (a), the stream is divided in six reach segments which are presented through their respective reduced distance (RD) 
in an order from the headwater reach to the most downstream reach of the system. The six reaches of the stream are as follows:

1. MS-HEAD

2. MS 100 - MS 80

3. MS 80 - MS 60

4. MS 60 - MS 40

5. MS 40 - MS 20

6. MS 20 - MS 00

The flow direction is from head reach (at $100 \mathrm{Km}$ ) towards downstream point at 0 $\mathrm{Km}$. Each reach is assigned its serial number ( 1 to 6$)$ as given above. Each reach is further divided into equal elements. Every element is denoted by a relevant element type number. In this example, all six reaches are divided into 51 computational elements or control volumes of equal lengths. The reach names, reach number, element number and element type of this example are shown in Figure 2.5 (b). In this example, we used only four types of elements. The first element number 1 and the last element number 51 belong to Type-1 and Type-5 category respectively. Elements number 2 and element number 22 belong to Type- 6 category because they both receive point inflows. The remaining elements are the standard elements of Type- 2 category.

\section{Fourth Step}

Finally, the input data is required to be entered in the software. The input data generally includes headwater characteristics, reaches, point sources, hydraulic data of the reaches, temperature module, water quality data (mean values), water quality data (minimum values), water quality data (maximum values), etc.

Once the system segment is defined and the input data is entered in the software, a data file is to be created to run QUAL2E model for sensitivity analysis and calibration of the model. On successful results of sensitivity analysis and calibration of the model, impact analysis of the desired discharges is conducted. 


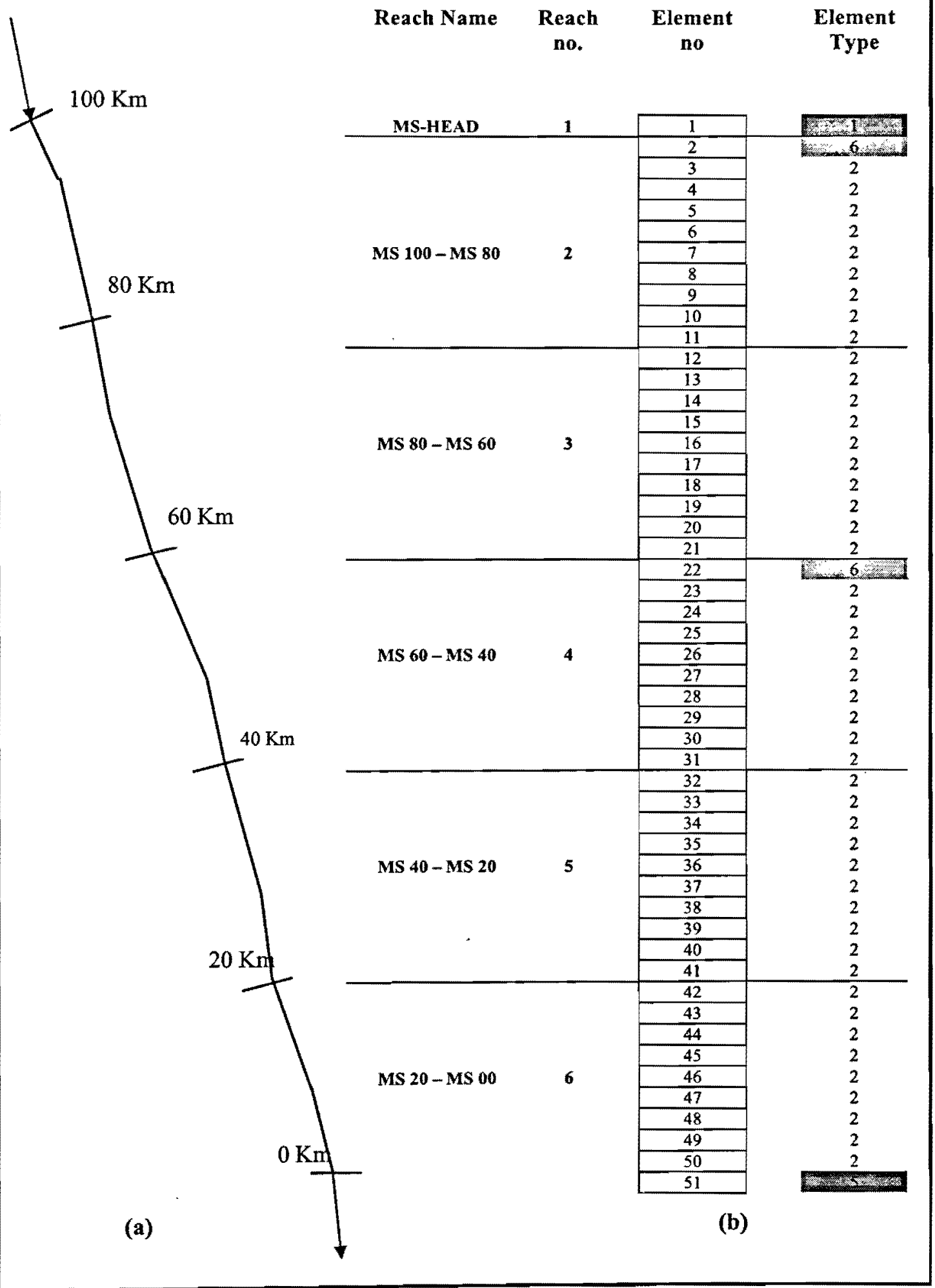

Figure 2.5 (a) A stream receiving pollutant loadings from a point source and tributary (b) QUAL2E segmentation scheme conforming to the stream shown in Figure (a) 


\subsection{QUAL2E Software Applications}

The QUAL2E is a one-dimensional mathematical model which is available as freeuse software to predict the water quality of a fluvial system. Applications of the QUAL2E to natural systems are found in the works of Van Orden and Uchrin (1993) to Whippany River, USA; Drolc and Koncan (1996) to Sava River, Slovenia; Ghosh and McBean (1998) to Kali River, India, Chaudhury et al. (1998) to Blackstone River, USA; Ciravolo et al. (2000) to Simeto River, Italy; Ning et al. (2001) to KaoPing River, Taiwan; Park and Lee (2002) to Nakdong River, South Korea; and Anh et al. (2006) to Nhue River, Vietnam among others. The model is numerically accurate and includes an updated kinetic structure for most conventional pollutants. The input and output data structures are designed in a user friendly format (Palmieri et al., 2006).

Park and Lee (2002) selected the QUAL2E as the best available model for use in the Nakdong River (South Korea) after a review of several water quality models. Although, QUAL2E has various advantages but some limitations of the model were also reported such as the lack of provision for conversion of algal death to BOD. Several modifications were made to overcome these limitations of QUAL2E. These modifications included the addition of new water quality interactions, such as conversion of algal death to BOD, de-nitrification, and DO change caused by fixed plants. In addition, the maximum number of reaches, computational elements, and junctions were extended to be applicable for a large river system.

\subsection{Surface Water Quality Indices}

The decision of water quality is a branch of multi-criteria decision analysis (MCDA) which is a set of systematic procedures for analyzing the complex decision problems (Malczewski, 1999). Keeping in view the MCDA for water quality, the water quality index (WQI) can be employed as a tool to translate the predicted water quality based on multiple variables into a single suitable criterion and established background levels of water quality based on the water quality standards for a given aquatic system (Ott, 1978). These water quality standards are easily understandable to the 
general audience. Efforts have been made to present more reliable water quality index to simplify the report and to improve the understanding of water quality issues by integrating complex data and to generate a single score that describes water quality status and evaluate water quality trends (Boyacioglu, 2007).

Since emergence of the concept of water quality index, which was first introduced in Germany in 1848 , a wide range of WQIs has been developed and applied to classify the quality of water in different regions (Terrado et al., 2010). The first formal water quality index was introduced by Horton in 1965 as 'Horton's Quality Index' (Horton, 1965). Thereafter, a number of water quality indices have been developed for general and specific uses. Examples are NSFWQI (Brown et al., 1970), Prati's Implicit Index (Prati et al., 1971), CCMEWQI (CCME, 2001), OWQI (Cude, 2002), and UWQI (Boyacioglu, 2007). However, all of these indices were developed to address the monitored aquatic systems. As such, they are not suitable for application to water that is not monitored, but they are suitable for application to water that can be simulated by water quality modeling (Song and Kim, 2009).

A consolidated list of indices for different water uses is given in Table 2.3. These indices have been broadly classified as physico-chemical indices, biological indices, and hydro-marphological indices. This study relates to physico-chemical indices class. In this study, NSFWQI, a widely used index, and Canadian water quality index CCMEWQI have been selected for their comparison to find the better index that can facilitate the decision-making process by translating the complex and obscure modeling result to a simple and intelligible description. 
Table 2.3 Classification of water-quality indices (WQIs)

\begin{tabular}{|c|c|c|}
\hline \multirow{43}{*}{$\begin{array}{l}\text { PHYSICOCHEMICAL } \\
\text { NDICES }\end{array}$} & \multirow{16}{*}{$\begin{array}{l}\text { Indices for } \\
\text { General } \\
\text { water quality }\end{array}$} & Horton's Index \\
\hline & & National Sanitation Foundations' Water Quality Index (NSFWQI) \\
\hline & & Prati's Implicit Index of Pollution \\
\hline & & McDuffie and Haney's River Pollution Index \\
\hline & & Diniu's Water Quality Index \\
\hline & & British Columbia Water Quality Index \\
\hline & & Oregon Water Quality Index (OWQI) \\
\hline & & Florida Stream Water Quality Index \\
\hline & & Overall Index of Pollution \\
\hline & & Pesce and Wunderlin's Water Quality Index \\
\hline & & Water Quality Index of Central Pollution Control Board \\
\hline & & River Pollution Index \\
\hline & & Universal Water Quality Index (UWQI) \\
\hline & & $\begin{array}{l}\text { Canadian Council of Ministers of the Environment's Water Quality Index } \\
\text { (CCMEWQ) }\end{array}$ \\
\hline & & Simplified Water Quality Index \\
\hline & & Said et al.'s Water Quality Index \\
\hline & \multirow{11}{*}{$\begin{array}{l}\text { Indices for } \\
\text { Specific } \\
\text { water uses }\end{array}$} & OConnor Indices: Fish and Wildlife Index and Public Water Supply Index \\
\hline & & Deininger and Landwehr Index for Public Water Supply \\
\hline & & Walski and Parker's Index for Recreation \\
\hline & & Stoner's Index for Dual Uses (PWS and Irrigation) \\
\hline & & Nemerow and Sumitomo's Pollution Index for Three Uses \\
\hline & & Smith's Index for Four Water Uses: 1) General; 2) Regular \\
\hline & & Public Bathing; 3) Water Supply; and, 4) Fish Spawning \\
\hline & & Viet and Bhargava's Index \\
\hline & & Gekov et al.'s Index \\
\hline & & Haire et al.'s Nutrient Loading Index and Eutrophication Index \\
\hline & & Li's Regional Water Resource Quality Assessment Index \\
\hline & \multirow{7}{*}{$\begin{array}{l}\text { Indices for } \\
\text { Planning }\end{array}$} & Truett et al. ${ }^{5} \mathrm{~s}$ Prevalence Duration Intensity Index \\
\hline & & Truett et al . ${ }^{\prime} s$ National Planning Priorities Index \\
\hline & & Truett et al.'s Priority Action Index \\
\hline & & Dee et al.'s Environmental Evaluation System \\
\hline & & Inhaber's Canadian National Index \\
\hline & & Zoeteman's Pollution Potential lndex \\
\hline & & Johansson and Johnson Pollution Index \\
\hline & \multirow{9}{*}{$\begin{array}{l}\text { Statistical } \\
\text { Approaches }\end{array}$} & Shoji et al.'s Composite Pollution Index \\
\hline & & Joung et al.'s Index of Partial Nutrients (Factor Analysis) \\
\hline & & Joung et al.'s Index of Total Nutrients (Factor Analysis) \\
\hline & & Coughlin et al.'s Principal Component Index (Principal Component Analysis) \\
\hline & & Shin and Lam (Principal Component Analysis) \\
\hline & & Parinet et al.'s (Principal Component Analysis) \\
\hline & & $\begin{array}{l}\text { Harkins's Index (Kendall Ranking Approach, 1975) (Non-Parametric } \\
\text { Classification) }\end{array}$ \\
\hline & & Schaeffer and Janardan's Beta Function Index \\
\hline & & Kung et al.'s Fuzzy Clustering \\
\hline \multirow{8}{*}{$\begin{array}{l}\text { BIOLOGICAL } \\
\text { INDICES }\end{array}$} & \multirow{2}{*}{$\begin{array}{l}\text { Macro- } \\
\text { Invertebrates }\end{array}$} & Biomonitoring Working Party \\
\hline & & Biological Families Index \\
\hline & \multirow{4}{*}{$\begin{array}{l}\text { Fish } \\
\text { Diatoms }\end{array}$} & Index of Biological Integrity \\
\hline & & Extended Biological Index (Adapted from Woodiwis (1978) Biological Index) \\
\hline & & Index of Sensitivity to Pollution (CEMAGREF, 1982) \\
\hline & & Biological Index of Diatoms \\
\hline & \multirow[t]{2}{*}{ Macrophytes } & Macrophytes Index \\
\hline & & Index of Macroscopic Aquatic Vegetation \\
\hline \multirow{5}{*}{$\begin{array}{l}\text { HYDRO-MORPHO- } \\
\text { LOGICAL } \\
\text { NDICES }\end{array}$} & Connectivity & Fluvial Connectivity Index \\
\hline & \multirow[t]{2}{*}{ Habitat } & Fluvial Habitat Index \\
\hline & & Qualitative Habitat Evaluation lndex \\
\hline & \multirow[t]{2}{*}{ Vegetation } & Fluvial Vegetation Index \\
\hline & & Bank Vegetation Quality Index \\
\hline
\end{tabular}

Source: Terrado, 2010 


\section{CHAPTER 3 \\ METHODOLOGY}

\subsection{General}

Water quality modeling is an ideal approach to simulate physical, chemical and biological changes in aquatic systems. It involves the prediction of water pollution using mathematical techniques. Song and Kim, 2009 have used QUAL2E modeling approach to simulate the pollutant loadings at Sapgyo River, South Korea. The simulated results were used to develop a newly introduced water quality index (WQI) termed as "QUAL2E water quality index (QWQLI)". Unlike other water quality indices, the QWQLI indexing was specifically used for simulated water quality using QUAL2E to mainly reflect pollutant loading levels.

Under this study, the work of Song and Kim, 2009 has been further elaborated and QWQLIs have been computed for all the elements of Sapgyo River by applying NSFWQI system approach. Additionally, the same pollutant loading results of Sapgyo River simulated by QUAL2E model, have been used to compute the QWQLIs for all the elements of Sapgyo River by applying CCMEWQI system approach. The QWQLI results obtained by applying the two NSFWQI and CCMEWQI systems approaches have been discussed in detail and compared to find the better result. Finally, a decision-making process has been suggested on the basis of better found QWQLI result.

\subsection{Study Site}

The study site is the main channel of the Sapgyo River in South Korea as shown in Figure 3.1. This is a longest tributary of the Geum River System in the country. The main channel is approximately $31 \mathrm{Km}$ long which flows in North-East direction. The flow rate of the river fluctuates from 120 to $160 \mathrm{~m}^{3} / \mathrm{sec}$ in rainy season. There are number of point sources along the river due to population, industry, livestock, and fisheries. Non-point sources are also exists due to land uses. Hence, point and nonpoint sources both discharge water pollutants into the river. In 2004, the Ministry of 
the Environment, South Korea had observed the average concentrations of the pollutants as given in Table 3.1. It was seriously noticed that the water quality of the river has been declining over the last more than ten years.

Table 3.1 Average concentration of the pollutants observed in 2004

\begin{tabular}{|ll|}
\hline Pollutants & Average Concentration \\
\hline Dissolved oxygen (DO) & 8.100 to $9.600 \mathrm{mg} / \mathrm{L}$ \\
\hline Biochemical oxygen demand (BOD) & 2.900 to $3.400 \mathrm{mg} / \mathrm{L}$ \\
\hline Carbonaceous oxygen demand (COD) & 4.800 to $4.900 \mathrm{mg} / \mathrm{L}$ \\
\hline Total nitrogen (T-N) & 1.600 to $1.700 \mathrm{mg} / \mathrm{L}$ \\
\hline Total phosphorous (T-P) & 0.029 to $0.034 \mathrm{mg} / \mathrm{L}$ \\
\hline
\end{tabular}

Source: Song and Kim, 2009

\subsection{QUAL2E Modeling}

The river water quality has been modeled as function of waste-loadings using software of QUAL2E model. As shown in Figure 3.2, the main channel is divided into five reaches which are further subdivided into 31 elements of equal length. The length of each element is $1 \mathrm{Km}$. The elements are conceptualized with their sequence and assigned flag numbers. The different types of elements and their assigned flag numbers are given in Table 3.2 . 


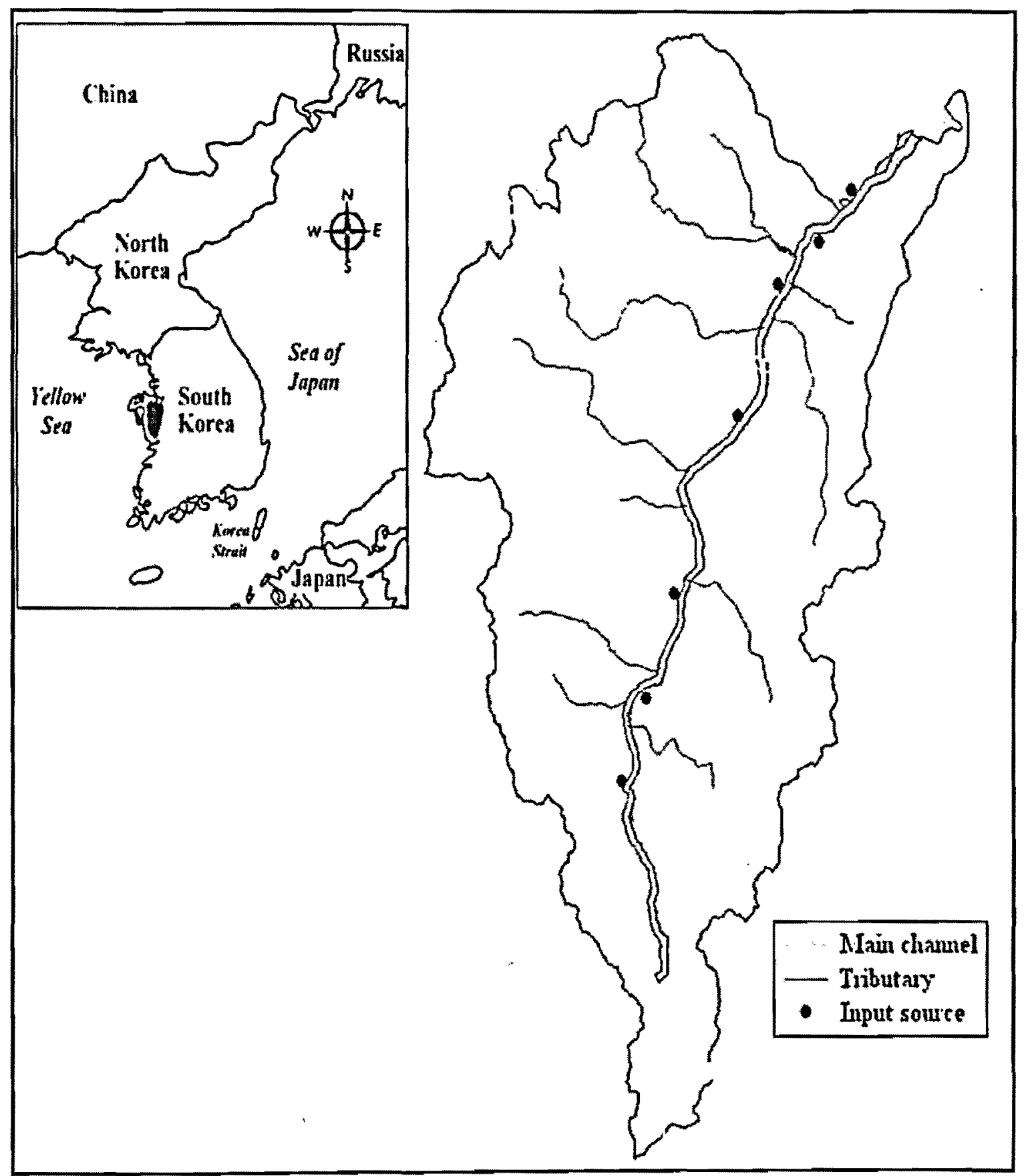

Figure 3.1 Site map - location of River Sapgyo in South Korea

Source: Song and Kim, 2009 


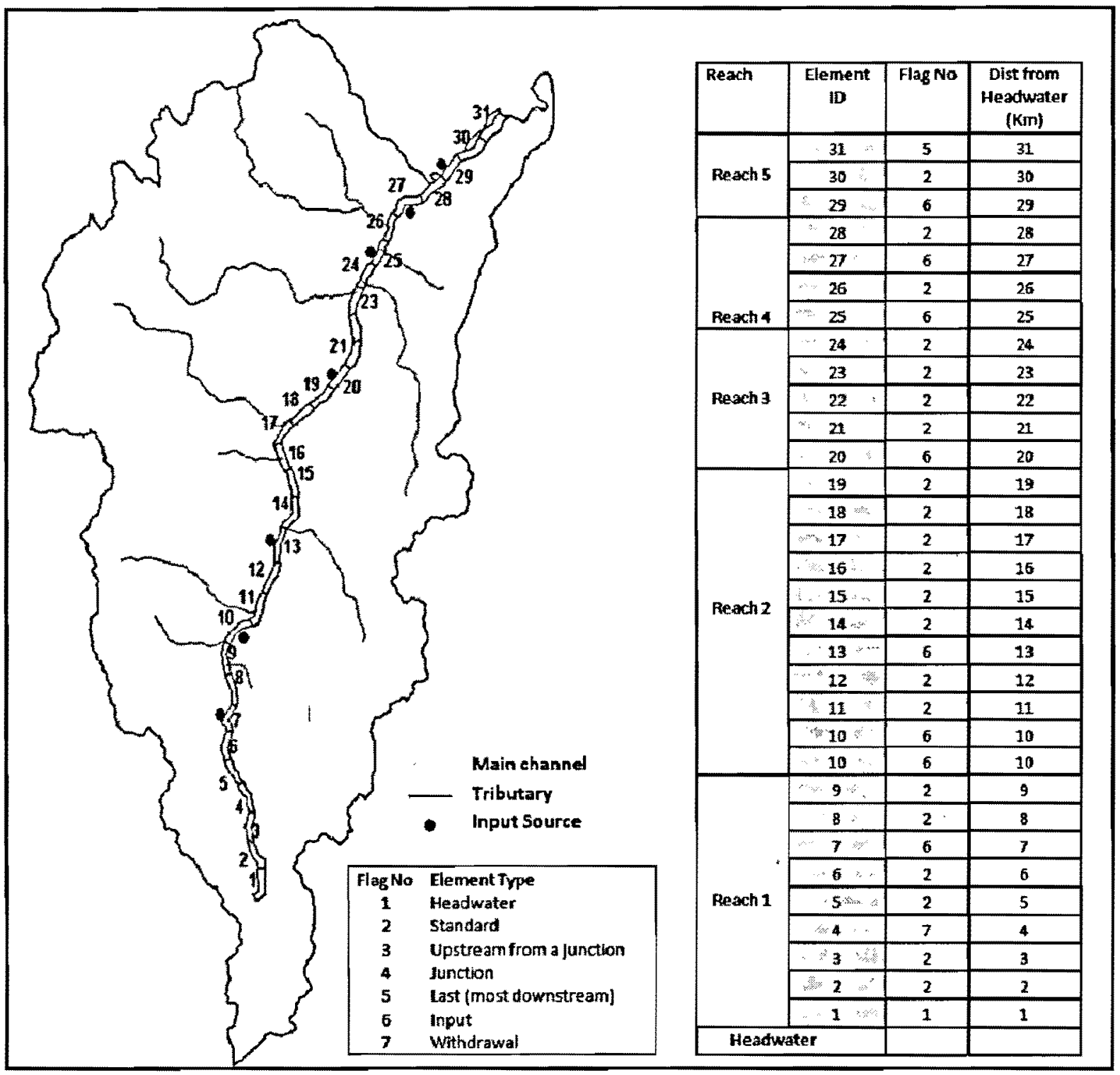

Figure 3.2 QUAL2E representations as reaches and elements of Sapgyo River Source: Song and $\mathrm{Kim}, 2009$ 
Table 3.2 Element types and assigned flag numbers

\begin{tabular}{|c|c|c|}
\hline $\begin{array}{l}\text { Element } \\
\text { Type }\end{array}$ & $\begin{array}{l}\text { Flag } \\
\text { Number }\end{array}$ & $\begin{array}{l}\text { Element } \\
\text { Number }\end{array}$ \\
\hline Headwater element & 1 & 1 \\
\hline Input elements & 6 & $7,10,13,20,25,27$, and 29 \\
\hline Withdrawal element & 7 & 4 \\
\hline Standard elements & 2 & $\begin{array}{l}2,3,5,6,8,9,11,12,14 \text { to } 19,21 \text { to } 24,26 \text {, } \\
28,30\end{array}$ \\
\hline Last Element in System & 5 & 31 \\
\hline
\end{tabular}

For each input source, the input pollutants have been regarded as the pollutant discharge by the area in which the source is located. The pollutants' load of headwater and input sources along the Sapgyo River before entering into their respective treatment plants is given in Table 3.3. Each source has its own water treatment plant (WTP) through which the pollutants can be mitigated to the desired level. The amount of pollutants, being discharged into the river, is calculated after the treatment through WTP facility. The generated pollutants have been computed to evaluate the water quality scales or water quality indices (WQIs) of the point sources and non-point sources which are generating the pollutants.

Table 3.3 Pollutant's load of headwater and input sources before entering into WTPs

\begin{tabular}{|l|l|l|r|r|r|r|}
\hline \multicolumn{2}{|l|}{ Input Source } & Location & Junction & \multicolumn{3}{c|}{ Pollutant Loads (mg/L) } \\
\cline { 5 - 7 } & & & \multicolumn{1}{c|}{ BOD } & \multicolumn{1}{c|}{ T-N } & T-P \\
\hline 1 & Headwater & Janggok Myeon & 1 & 6.100 & 2.588 & 0.103 \\
\hline 2 & Point Source 1 & Hongdong Myeon & 7 & 5.244 & 8.873 & 0.465 \\
\hline 3 & Point Source 2 & Hongseong Eup & 10 & 5.244 & 8.873 & 0.465 \\
\hline 4 & Point Source 3 & Hongbuk Myeon & 13 & 17.020 & 28.697 & 3.880 \\
\hline 5 & Point Source 4 & Sapgyo Eup & 20 & 2.429 & 9.969 & 0.205 \\
\hline 6 & Point Source 5 & Oga Myeon & 25 & 1.416 & 7.351 & 0.132 \\
\hline 7 & Point Source 6 & Godeok Myeon & 27 & 1.416 & 7.351 & 0.132 \\
\hline 8 & Point Source 7 & Sinam Myeon & 29 & 0.780 & 4.584 & 0.074 \\
\hline
\end{tabular}

Source: Song and Kim, 2009 
The BOD concentration to be measured at downstream from the WTPs can be simulated by the following equation (Liu and Chen, 2009):

$$
\mathrm{BOD}_{(\mathrm{t})}=\mathrm{BOD}_{(0)} \mathrm{e}^{-k t}
$$

Where, $\mathrm{BOD}_{(\mathrm{t})}=\mathrm{BOD}$ Concentration in $\mathrm{mg} / \mathrm{L}$ at time $\mathrm{t}$ in the water.

$$
\begin{aligned}
\mathrm{BOD}_{(0)}= & \text { BOD Concentration in } \mathrm{mg} / \mathrm{L} \text { at initial time in the stream. } \\
\mathrm{t}= & \text { time in days for the waste traveling from the plant to downstream } \\
& \text { point of interest. } \\
\mathrm{k}= & \text { de-oxygenation rate constant per day for BOD degradation } \\
& \quad \text { (generally assume } 0.10 / \text { day). }
\end{aligned}
$$

As mentioned in Section 2.1, QUAL2E can simulate 15 constituents. But in case of Sapgyo River, only 10 out of 15 constituents are involved in the modeling process which are listed below:

(i) Dissolved Oxygen (DO)

(ii) Biochemical Oxygen Demand (BOD)

(iii) Temperature

(iv) Algae as Chlorophyll a

(v) Organic Nitrogen as $\mathrm{N}$

(vi) Ammonia $\left(\mathrm{NH}_{4}\right)$ as $\mathrm{N}$

(vii) Nitrite $\left(\mathrm{NO}_{2}\right)$ as $\mathrm{N}$

(viii) Nitrate $\left(\mathrm{NO}_{3}\right)$ as $\mathrm{N}$

(ix) Organic Phosphorous as $\mathrm{P}$

(x) Dissolved Phosphorous $\left(\mathrm{PO}_{4}\right)$ as $\mathrm{P}$

The total amount of four types of nitrogen (organic nitrogen, ammonia, nitrite and nitrate) in water can be indicated as T-N (total nitrogen). Similarly, the total amount of two types of phosphorous (organic phosphorous and dissolved phosphorous) in water can be indicated as T-P (total phosphorous). The modeling result using simulated data is given in Table 3.4 . 
Table 3.4 QUAL2E modeling result of the Sapgyo River (2004)

\begin{tabular}{|c|c|c|c|c|c|c|c|c|c|c|c|c|}
\hline ID & $\begin{array}{c}\text { Temp. } \\
\left({ }^{\circ} \mathrm{C}\right)\end{array}$ & $\begin{array}{c}\text { Do } \\
\text { (mg/L) }\end{array}$ & $\begin{array}{c}\text { BOD } \\
(m g / L)\end{array}$ & $\underset{(m g / L)}{N}$ & $\begin{array}{l}\text { NH4-N } \\
(\mathrm{mg} / \mathrm{L})\end{array}$ & $\begin{array}{l}\text { NO2-N } \\
(\mathrm{mg} / \mathrm{L})\end{array}$ & $\begin{array}{l}\text { NO3-N } \\
\text { (mg/L) }\end{array}$ & $\begin{array}{c}T-N \\
(\mathrm{mg} / \mathrm{L})\end{array}$ & $\underset{(\mathrm{mg} / \mathrm{L})}{\mathrm{P}}$ & $\begin{array}{l}\text { PO4-P } \\
(\mathrm{mg} / \mathrm{L})\end{array}$ & $\begin{array}{c}\mathrm{T}-\mathrm{P} \\
(\mathrm{mg} / \mathrm{L})\end{array}$ & $\begin{array}{c}\text { Chl-a } \\
\text { (mg/L) }\end{array}$ \\
\hline 1 & 11.59 & 11.15 & 5.75 & 0.649 & 0.315 & 0.000 & 1.601 & 2.565 & 0.023 & 0.075 & 0.098 & 1.46 \\
\hline 2 & 12.09 & 10.76 & 5.42 & 0.626 & 0.315 & 0.000 & 1.601 & 2.543 & 0.019 & 0.075 & 0.095 & 1.47 \\
\hline 3 & 12.51 & 10.58 & 5.10 & 0.604 & 0.316 & 0.001 & 1.601 & 2.521 & 0.016 & 0.075 & 0.091 & 1.48 \\
\hline 4 & 12.87 & 10.47 & 4.78 & 0.581 & 0.316 & 0.001 & 1.601 & 2.499 & 0.013 & 0.075 & 0.088 & 1.49 \\
\hline 5 & 13.15 & 10.39 & 4.50 & 0.561 & 0.316 & 0.001 & 1.601 & 2.479 & 0.011 & 0.075 & 0.086 & 1.50 \\
\hline 6 & 13.39 & 10.34 & 4.23 & 0.541 & 0.317 & 0.001 & 1.603 & 2.463 & 0.009 & 0.075 & 0.084 & 1.51 \\
\hline 7 & 14.57 & 10.77 & 4.81 & 1.796 & 0.872 & 0.001 & 4.439 & 7.108 & 0.086 & 0.267 & 0.353 & 1.47 \\
\hline 8 & 14.58 & 10.32 & 4.59 & 1.748 & 0.874 & 0.001 & 4.439 & 7.062 & 0.075 & 0.267 & 0.342 & 1.49 \\
\hline 9 & 14.59 & 10.10 & 4.38 & 1.702 & 0.875 & 0,002 & 4.439 & 7.018 & 0.066 & 0.267 & 0.333 & 1.50 \\
\hline 10 & 14.72 & 10.34 & 4.49 & 1.860 & 0.942 & 0.002 & 4.783 & 7.586 & 0.077 & 0.290 & 0.367 & 1.49 \\
\hline 11 & 14.72 & 10.10 & 4.30 & 1.815 & 0.943 & 0.002 & 4.783 & 7.543 & 0.068 & 0.290 & 0.358 & 1.50 \\
\hline 12 & 14.72 & 9.97 & 4.12 & 1.771 & 0.944 & 0.003 & 4.783 & 7.500 & 0.060 & 0.290 & 0.350 & 1.51 \\
\hline 13 & 14.71 & 9.90 & 3.96 & 1.734 & 0.948 & 0.003 & 4.797 & 7.482 & 0.054 & 0.294 & 0.347 & 1.53 \\
\hline 14 & 17,71 & 9.87 & 3.80 & 1.693 & 0.949 & 0.003 & 4,797 & 7.442 & 0.047 & 0.294 & 0.341 & 1.54 \\
\hline 15 & 14.71 & 9.86 & 3.64 & 1.652 & 0.949 & 0.004 & 4.797 & 7.402 & 0.042 & 0.294 & 0.336 & 1.55 \\
\hline 16 & 14.71 & 9.85 & 3.48 & 1,612 & 0.950 & 0.004 & 4.797 & 7.364 & 0.037 & 0.294 & 0.331 & 1.56 \\
\hline 17 & 14.71 & 9.86 & 3.34 & 1.573 & 0.951 & 0.005 & 4.797 & 7.326 & 0.033 & 0.294 & 0.326 & 1.57 \\
\hline 18 & 14.70 & 9.87 & 3.20 & 1.535 & 0.952 & 0.005 & 4.797 & 7.290 & 0.029 & 0.294 & 0.322 & 1.58 \\
\hline 19 & 14.70 & 9.88 & 3.06 & 1.499 & 0.953 & 0.006 & 4.798 & 7.255 & 0.025 & 0.294 & 0.319 & 1.60 \\
\hline 20 & 14.81 & 10.36 & 2.81 & 1.868 & 1.056 & 0.004 & 5.343 & 8.272 & 0.034 & 0.236 & 0.270 & 1.55 \\
\hline 21 & 14.79 & 10.20 & 2.80 & 1.769 & 1.058 & 0.005 & 5.343 & 8.176 & 0.029 & 0.236 & 0.265 & 1.58 \\
\hline 22 & 14.77 & 10.14 & 2.79 & 1.676 & 1.060 & 0.007 & 5.343 & 8.086 & 0.025 & 0.236 & 0.261 & 1.60 \\
\hline 23 & 14.76 & 10.12 & 2.79 & 1.587 & 1.062 & 0.008 & 5.343 & 8.001 & 0.022 & 0.236 & 0.258 & 1.63 \\
\hline 24 & 14.75 & 10.11 & 2.78 & 1.504 & 1.064 & 0.009 & 5.343 & 7.920 & 0.019 & 0.236 & 0.255 & 1.65 \\
\hline 25 & 14.79 & 10.63 & 2.84 & 1.683 & 1.035 & 0.008 & 5.202 & 7.928 & 0.030 & 0.211 & 0.241 & 1.64 \\
\hline 26 & 14.78 & 10.77 & 3.03 & 1.748 & 1.035 & 0.009 & 5.202 & 7.994 & 0.036 & 0.211 & 0.247 & 1.65 \\
\hline 27 & 14.81 & 11.02 & 2.96 & 1.835 & 1.014 & 0.008 & 5.104 & 7.961 & 0.042 & 0.194 & 0.236 & 1.63 \\
\hline 28 & 14.81 & 11.10 & 3.15 & 1.903 & 1.015 & 0.008 & 5.103 & 8.029 & 0.050 & 0.194 & 0.244 & 1.64 \\
\hline 29 & 14.84 & 11.18 & 2.85 & 1.850 & 0.943 & 0.007 & 4.745 & 7.545 & 0.046 & 0.172 & 0.218 & 1.62 \\
\hline 30 & 14.83 & 11.14 & 2.95 & 1.916 & 0.944 & 0.007 & 4.745 & 7.612 & 0.048 & 0.172 & 0.219 & 1.63 \\
\hline 31 & 14.83 & 11.10 & 3.04 & 1.983 & 0.945 & 0.008 & 4.745 & 7.680 & 0.049 & 0.172 & 0.221 & 1.64 \\
\hline
\end{tabular}

Source: Song and Kim, 2009 


\subsection{Model Calibration}

The oxidation and settling rates of BOD and different existing types of nitrogen and phosphorous were calibrated so that these can be validated from the observed data. Algal photosynthesis and sediment oxygen demand (SOD) were also considered due to their direct effect on the dissolved oxygen (DO).

\subsection{Model Validation}

The modeling results were validated on the two selected monitoring stations located at element number 23 (SR1) and element number 29 (SR2) along the river. At these two stations, the water quality data was monitored during each month for the period from 2000 to 2004 . The comparison of the simulated results and respective observed data for BOD, T-Ns and T-Ps is presented in Figures 3.3, 3.4 and 3.5 respectively.

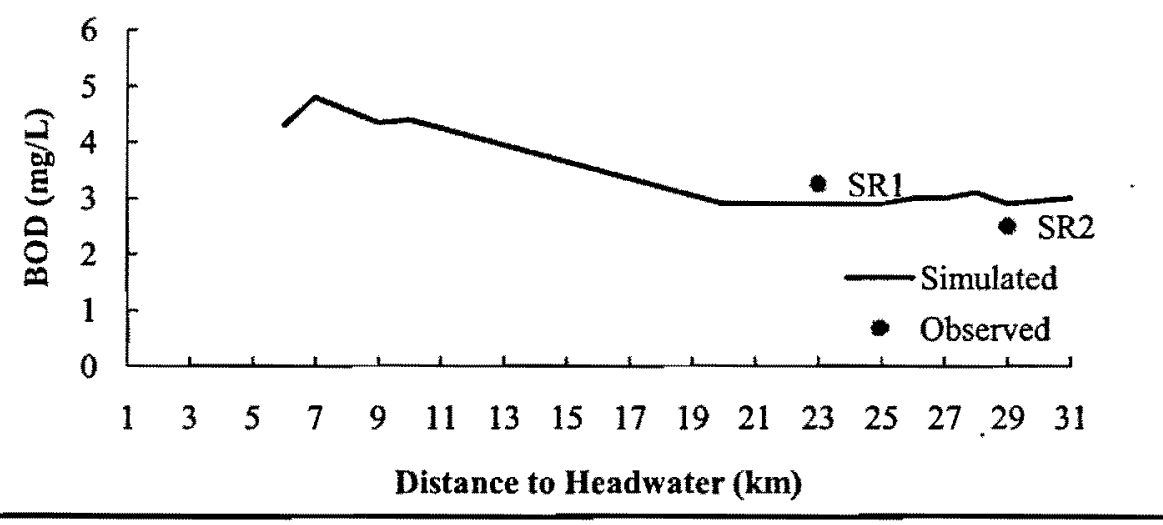

Figure 3.3 Simulated and observed data of BOD 


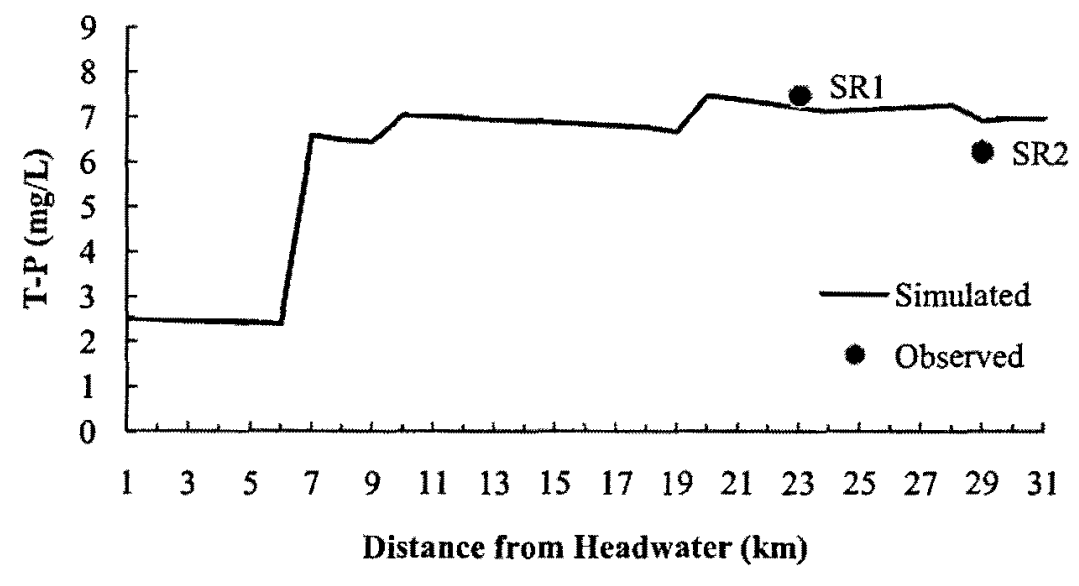

Figure 3.4 Simulated and observed data of T-P

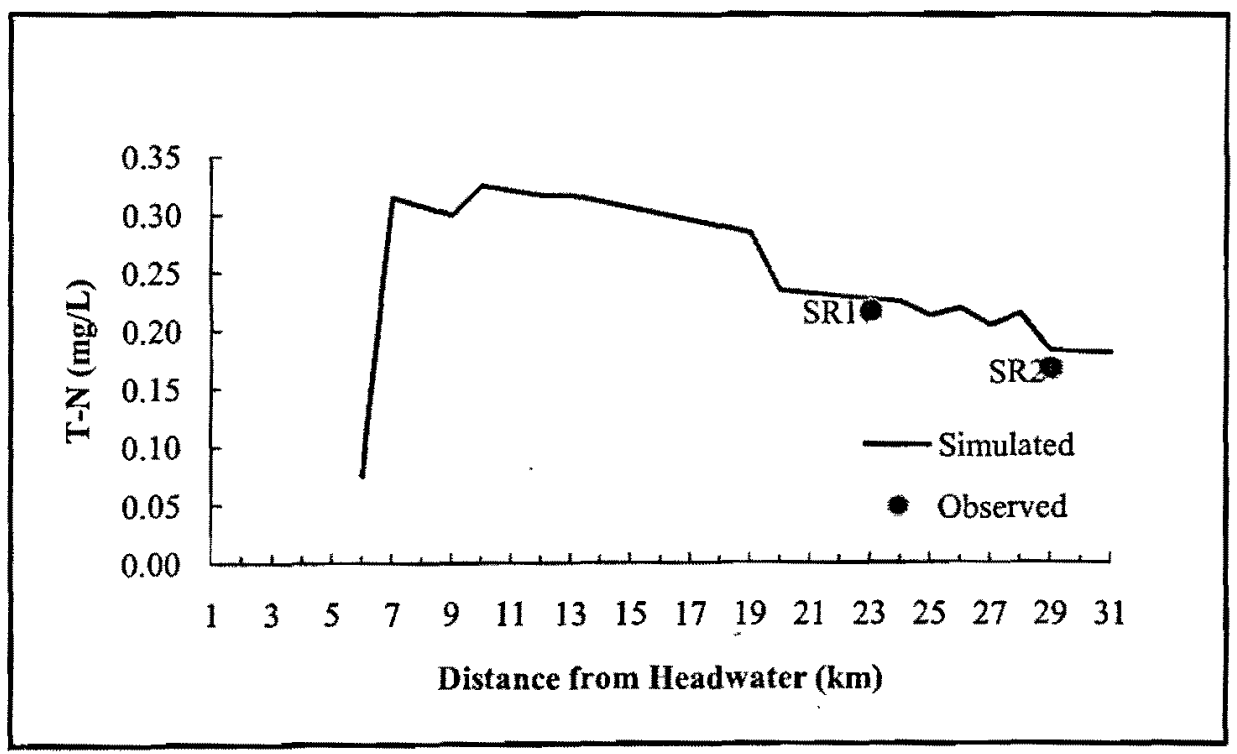

Figure 3.5 Simulated and observed data of T-N

Figures $3.3,3.4$ and 3.5 show that the simulation curves rises sharply at element 7 , where pollutant source number 1 is located. This shows that the discharged pollutants for this source are causing a steep decline in water quality. Moreover, a slight discrepancy between the simulated and observed values exists at the two selected monitoring stations. As a whole, the modeling result reflects the water quality trend along the main channel. 


\subsection{Determination of QUAL2E Water Quality Loading Index by Applying NSFWQI Approach}

QUAL2E water quality loading index (QWQLI) is a newly developed water quality index to provide a simple description of the water quality modeling result from QUAL2E model. QWQLI has specific applicability to water that is not monitored but can be simulated by QUAL2E model (Song and Kim, 2009).

Normally, the development of a WQI includes four steps:

\section{First Step}

The relevant water quality variables are selected.

\section{Second Step}

A set of sub-index functions is defined to transform each variable to a common scale.

\section{Third Step}

Each variable is assigned a weight value to denote its importance to overall water quality.

\section{Fourth Step}

All of the sub indices are aggregated by a specific aggregation operator.

These four steps have been further explained in the forthcoming sections:

\subsubsection{Variable Selection}

There are ten parameters that have been simulated by QUAL2E to represent the water quality of the river. Out of these simulated parameters only BOD, T-N, and T$P$ have been categorized as the important indicators of oxygen depletion caused by water pollutants. They have a more direct relationship to input pollutants than other indicators. In a sense, these are the major indicative parameters to simplify the description of simulated water quality by QUAL2E and help decision-makers to 
design improvement actions on pollutant loads. Therefore, these three parameters have been selected as the variables of QWQLI indexing.

\subsubsection{Sub-index Determination}

The QWQLI quality rating consists of five classes as excellent, good, medium, bad and very bad. In order to indicate the pollutant loading levels, the descriptors of classes from I to $\mathrm{V}$ have been altered to very low, low, medium, high and very high, respectively. The five-class standards of $\mathrm{BOD}_{5}, \mathrm{~T}-\mathrm{N}$ and T-P are listed in Table 3.5

Table 3.5 Five-class standards of BOD, T-N, and T-P and their descriptors for NSFWQI Indexing

\begin{tabular}{|l|l|l|l|l|l|}
\hline Variable & $\begin{array}{l}\text { Class I } \\
\text { (very low) }\end{array}$ & $\begin{array}{l}\text { Class II } \\
\text { (low) }\end{array}$ & $\begin{array}{l}\text { Class III } \\
\text { (medium) }\end{array}$ & $\begin{array}{l}\text { Class IV } \\
\text { (high) }\end{array}$ & $\begin{array}{l}\text { Class V } \\
\text { (very high) }\end{array}$ \\
\hline $\mathrm{BOD}(\mathrm{mg} / \mathrm{L})$ & $0<\mathrm{X}<1$ & $1 \leq \mathrm{X}<3$ & $3 \leq \mathrm{X}<6$ & $6 \leq \mathrm{X}<8$ & $8 \leq \mathrm{X}<10$ \\
\hline $\mathrm{T}-\mathrm{N}(\mathrm{mg} / \mathrm{L})$ & $0<\mathrm{X}<2$ & $2 \leq \mathrm{X}<4$ & $4 \leq \mathrm{X}<6$ & $6 \leq \mathrm{X}<10$ & $10 \leq \mathrm{X}<15$ \\
\hline T-P $(\mathrm{mg} / \mathrm{L})$ & $0<\mathrm{X}<0.1$ & $0.1 \leq \mathrm{X}<0.3$ & $0.3 \leq \mathrm{X}<0.5$ & $0.5 \leq \mathrm{X}<1.0$ & $1.0 \leq \mathrm{X}<1.5$ \\
\hline
\end{tabular}

Source: Song and Kim, 2009

Brown et al. (1970) presented the National Sanitation Foundation Water Quality Index (NSFWQI) which is the most widely used index amongst all existing water quality indices. By means of the NSFWQI each class can be represented by a numerical range as given below:

$\begin{array}{lllll}\text { Class I } & \text { Class II } & \text { Class III } & \text { Class IV } & \text { Class V } \\ 91 \text { to } 100 & 71 \text { to } 90 & 51 \text { to } 70 & 26 \text { to } 50 & 0 \text { to } 25\end{array}$

Sub-indices are value functions to transform the different units and dimensions of water quality variables to a common scale for a multi-criteria analysis. The relation of the value of water quality variable $\mathrm{X}$ and its corresponding sub-index $\mathrm{Y}$ is given in Table 3.6 for BOD, T-N and T-P. Where, $\mathrm{X}$ is the value of water quality variable and $\mathrm{Y}$ is its sub-index. 
Table 3.6 Sub-index functions for QWQLI indexing

\begin{tabular}{|c|c|c|}
\hline Vabse & Bange & stibntes tuston \\
\hline \multirow[t]{7}{*}{$\mathrm{BOD}$} & $x=0$ & $Y=100$ \\
\hline & $0<X<1$ & $Y=-10 X+100$ \\
\hline & $1 \leq x<3$ & $Y=-10 X+100$ \\
\hline & $3 \leq X<6$ & $Y=-6.7 X+90.1$ \\
\hline & $6 \leq X<8$ & $Y=-12.5 X+125$ \\
\hline & $8 \leq X<10$ & $Y=-12.5 X+125$ \\
\hline & $x \geq 10$ & $Y=0$ \\
\hline \multirow[t]{7}{*}{$\mathrm{T}-\mathrm{N}$} & $x=0$ & $Y=100$ \\
\hline & $0<X<2$ & $Y=-5 X+100$ \\
\hline & $2 \leq x<4$ & $Y=-10 X+110$ \\
\hline & $4 \leq x<6$ & $Y=-10 X+110$ \\
\hline & $6 \leq X<10$ & $Y=-6.25 X+87.5$ \\
\hline & $10 \leq x<15$ & $Y=-5 X+75$ \\
\hline & $x \geq 15$ & $Y=0$ \\
\hline \multirow[t]{7}{*}{ T-P } & $X=0.0$ & $Y=100$ \\
\hline & $0.0<X<0.1$ & $Y=-100 X+100$ \\
\hline & $0.1 \leq x<0.3$ & $Y=-100 X+100$ \\
\hline & $0.3 \leq X<0.5$ & $Y=-100 X+100$ \\
\hline & $0.5 \leq X<1.0$ & $Y=50 X \leq 25$ \\
\hline & $1.0 \leq X<1.5$ & $Y=-50 X+75$ \\
\hline & $x \geq 1.5$ & $Y=0$ \\
\hline
\end{tabular}

Source: Song and Kim, 2009

\subsubsection{Weight Assignments}

The purpose of weight assignments to water quality variables is to denote the importance of each variable to the overall water quality. A larger weight value has greater importance of the variable. In assigning the weight of each variable, the most challenging factor is that the different people may have different opinions. The weight assignment of the NSFWQI reflects the opinions of a panel of 142 experts in water quality management (Song and Kim, 2009). Each expert evaluates the importance of every variable based on his opinion. Therefore, the worldwide used NSFWQI significance ratings have been followed to assign the weight to water quality variables. According to this rating, the weights of BOD, T-N and T-P have been assigned and further normalized by the following equations: 


$$
\begin{aligned}
& w_{i}^{\prime}=\frac{r_{\text {Lowest }}}{r_{i}} \\
& w_{i}=\frac{w_{i}^{\prime}}{\sum_{i=1}^{3} w_{i}^{\prime}}
\end{aligned}
$$

Where, $\quad r_{\text {Lowest }}=$ lowest significant rating amongst BOD, T-N and T-P

$r_{i}=$ Individual significant rating value of BOD, T-N and T-P

$w_{i}^{\prime} \quad=$ Individual temporary weight of $\mathrm{BOD}, \mathrm{T}-\mathrm{N}$ and $\mathrm{T}-\mathrm{P}$

$w_{i} \quad=$ Individual final (normalized) weight of BOD, T-N and T-P

\subsubsection{Sub-Index Aggregation}

Most multi criteria decision problems require aggregation ("andness" or "orness") of the decision criteria. The sub-index aggregation of a WQI mathematically combines sub-indices to form an overall index value. The aggregation function of QWQLI is a linear sum aggregation function as given in the following equation:

$$
Q W Q L I=\sum_{i=1}^{3} w_{i} I_{i}
$$

Where, $I_{i}$ is the individual actual loading of the pollutants BOD, T-P and T-N.

Therefore, the aggregation function of QWQLI can be written as follows:

$$
Q W Q L I=w_{B O D} I_{B O D}+w_{T N} I_{T N}+w_{T P} I_{T P}
$$

Where, $\quad w_{B O D}=$ weight value of $\mathrm{BOD}, \quad I_{B O D}=$ sub-index of $\mathrm{BOD}$

$$
\begin{array}{ll}
w_{T N}=\text { weight value of } \mathrm{T}-\mathrm{N}, & I_{T N}=\text { sub-index of T-N } \\
w_{T P}=\text { weight value of } \mathrm{T}-\mathrm{P}, & I_{T P}=\text { sub-index of T-P }
\end{array}
$$




\subsubsection{Computation of QWQLI with Application of NSFWQI System Approach}

The QUAL2E modeling results provided in Table 3.4 have been indexed in Table 3.8 following the procedures explained in sections 3.5.1 to 3.5.4. As shown in Table 3.8, the BOD, T-N, and T-P values of each element have been sub-indexed by applying the concerned function equation as provided in Table 3.6.

The weight assignment has been provided in Table 3.7 using NSFWQI significance rating factor for QWQLI indexing.

Table 3.7 Weight assignment for QWQLI indexing

\begin{tabular}{|c|c|c|c|}
\hline \\
\hline \\
\hline \multicolumn{4}{|c|}{$\begin{array}{llll}\text { T-N } & 2.4 & \frac{2.3}{2.4}=0.96 & \frac{0.96}{1.00+0.96+0.96}=0.33\end{array}$} \\
\hline T-P & 2.4 & $\frac{2.3}{2.4}=0.96$ & $\frac{0.96}{1.00+0.96+0.96}=0.33$ \\
\hline
\end{tabular}

Thereafter, the QWQLI has been calculated for each element using equation (3.5) and further classified using five-class descriptors. 
Table 3.8 Calculations of QWQLI using NSFWQI system approach

\begin{tabular}{|c|c|c|c|c|c|c|c|c|c|}
\hline \multirow[t]{2}{*}{ ID } & \multicolumn{2}{|c|}{ BOD } & \multicolumn{2}{|c|}{$\mathbf{T}-\mathbf{N}$} & \multicolumn{2}{|c|}{ T-P } & \multirow{2}{*}{$\begin{array}{c}\text { QWQLI } \\
\left(0.34 Y_{1}+\right. \\
0.33 Y 2 \\
+0.33 Y 3)\end{array}$} & \multirow[t]{2}{*}{ Class } & \multirow{2}{*}{$\begin{array}{l}\text { Pollutant } \\
\text { Loading } \\
\text { Level }\end{array}$} \\
\hline & $\begin{array}{l}\text { Loading } \\
(\mathrm{x}) \\
\mathrm{mg} / \mathrm{L}\end{array}$ & $\begin{array}{c}\text { Sub- } \\
\text { Index } \\
\text { Function } \\
\text { (Y1) }\end{array}$ & $\begin{array}{l}\text { Loading } \\
(\mathrm{X}) \\
\mathrm{mg} / \mathrm{L}\end{array}$ & $\begin{array}{l}\text { Sub- } \\
\text { Index } \\
\text { Function } \\
\text { (Y2) }\end{array}$ & $\begin{array}{l}\text { Loading } \\
(\mathrm{X}) \\
\mathrm{mg} / \mathrm{L}\end{array}$ & $\begin{array}{c}\text { Sub- } \\
\text { Index } \\
\text { Function } \\
\text { (Y3) }\end{array}$ & & & \\
\hline 1 & 5.75 & 51.6 & 2.6 & 84.4 & 0.098 & 90.2 & 75.2 & II & Low \\
\hline 2 & 5.42 & 53.8 & 2.5 & 84.6 & 0.095 & 90.5 & 76.1 & 11 & Low \\
\hline 3 & 5.10 & 55.9 & 2.5 & 84.8 & 0.091 & 90.9 & 77.0 & 11 & Low \\
\hline 4 & 4.78 & 58.1 & 2.5 & 85.0 & 0.088 & 91.2 & 77.9 & II & Low \\
\hline 5 & 4.50 & 60.0 & 2.5 & 85.2 & 0.086 & 91.4 & 78.7 & II & Low \\
\hline 6 & 4.23 & 61.8 & 2.5 & 85.4 & 0.084 & 91.6 & 79.4 & II & Low \\
\hline 7 & 4.81 & 57.9 & 7.1 & 43.1 & 0.353 & 64.7 & 55.3 & III & Medium \\
\hline 8 & 4.59 & 59.3 & 7.1 & 43.4 & 0.342 & 65.8 & 56.3 & III & Medium \\
\hline 9 & 4.38 & 60.8 & 7.0 & 43.6 & 0.333 & 66.7 & 57.1 & III & Medium \\
\hline 10 & 4.49 & 60.0 & 7.6 & 40.1 & 0.367 & 63.3 & 54.6 & III & Medium \\
\hline 11 & 4.30 & 61.3 & 7.5 & 40.4 & 0.358 & 64.2 & 55.4 & III & Medium \\
\hline 12 & 4.12 & 62.5 & 7.5 & 40.6 & 0.350 & 65.0 & 56.2 & 111 & Medium \\
\hline 13 & 3.96 & 63.6 & 7.5 & 40.7 & 0.347 & 65.3 & 56.7 & III & Medium \\
\hline 14 & 3.80 & 64.6 & 7.4 & 41.0 & 0.341 & 65.9 & 57.3 & III & Medium \\
\hline 15 & 3.64 & 65.7 & 7.4 & 41.2 & 0.336 & 66.4 & 57.9 & III & Medium \\
\hline 16 & 3.48 & 66.8 & 7.4 & 41.5 & 0.331 & 66.9 & 58.5 & III & Medium \\
\hline 17 & 3.34 & 67.7 & 7.3 & 41.7 & 0.326 & 67.4 & 59.1 & III & Medium \\
\hline 18 & 3.20 & 68.7 & 7.3 & 41.9 & 0.322 & 67.8 & 59.6 & III & Medium \\
\hline 19 & 3.06 & 69.6 & 7.3 & 42.2 & 0.319 & 68.1 & 60.1 & 111 & Medium \\
\hline 20 & 2.81 & 71.9 & 8.3 & 35.8 & 0.270 & 73.0 & 60.4 & III & Medium \\
\hline 21 & 2.80 & 72.0 & 8.2 & 36.4 & 0.265 & 73.5 & 60.8 & III & Medium \\
\hline 22 & 2.79 & 72.1 & 8.1 & 37.0 & 0.261 & 73.9 & 61.1 & III & Medium \\
\hline 23 & 2.79 & 72.1 & 8.0 & 37.5 & 0.258 & 74.2 & 61.4 & III & Medium \\
\hline 24 & 2.78 & 72.2 & 7.9 & 38.0 & 0.255 & 74.5 & 61.7 & III & Medium \\
\hline 25 & 2.84 & 71.6 & 7.9 & 38.0 & 0.241 & 75.9 & 62.0 & III & Medium \\
\hline 26 & 3.03 & 69.8 & 8.0 & 37.5 & 0.247 & 75.3 & 61.0 & III & Medium \\
\hline 27 & 2.96 & 70.4 & 8.0 & 37.7 & 0.236 & 76.4 & 61.7 & III & Medium \\
\hline 28 & 3.15 & 69.0 & 8.0 & 37.3 & 0.244 & 75.6 & 60.8 & III & Medium \\
\hline 29 & 2.85 & 71.5 & 7.5 & 40.3 & 0.218 & 78.2 & 63.5 & III & Medium \\
\hline 30 & 2.95 & 70.5 & 7.6 & 39.9 & 0.219 & 78.1 & 63.0 & III & Medium \\
\hline 31 & 3.04 & 69.7 & 7.7 & 39.5 & 0.221 & 77.9 & 62.5 & III & Medium \\
\hline
\end{tabular}

Note:

Equation, $\mathrm{Y} 1=-6.7 \mathrm{X}+90.1$, is used for element numbers 1 to $19,26,28$, and 31 .

Equation, $Y 1=-10 X+100$, is used for element numbers 20 to $25,27,29$, and 30 .

Equation, $Y 2=-10 X+110$, is used for element numbers 1 to 6 .

Equation, $\mathrm{Y} 2=-6.25 \mathrm{X}+87.5$, is used for element numbers 7 to 31 .

Equation, $\mathrm{Y} 3=-100 \mathrm{X}+100$, is used for element numbers 1 to 31 . 


\subsection{Determination of QUAL2E Water Quality Loading Index by Applying CCMEWQI Approach}

The CCMEWQI system is based on a formula developed by the Ministry of Environment, Lands and Parks, British Columbia, Canada. The index gives water quality rating range from 0 (worst water quality) and 100 (best water quality). This rating range is divided into five descriptive category types and classes as shown in Table 3.9.

Table 3.9 CCMEWQI quality rating range, category type and quality condition

\begin{tabular}{|c|c|c|c|}
\hline 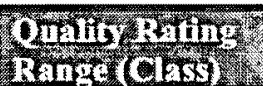 & Chtogis & 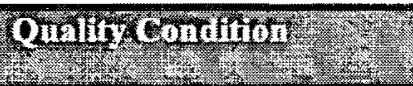 & 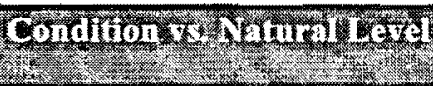 \\
\hline $\begin{array}{l}0 \text { to } 44 \\
\text { (V) }\end{array}$ & Poor & $\begin{array}{l}\text { Water quality is almost } \\
\text { always threatened and } \\
\text { impaired }\end{array}$ & $\begin{array}{l}\text { Conditions usually depart } \\
\text { from natural or desirable } \\
\text { levels }\end{array}$ \\
\hline $\begin{array}{l}44.1 \text { to } 64 \\
\text { (IV) }\end{array}$ & Marginal & $\begin{array}{l}\text { Water quality is frequently } \\
\text { threatened or impaired }\end{array}$ & $\begin{array}{l}\text { Conditions often depart from } \\
\text { natural or desirable levels }\end{array}$ \\
\hline $\begin{array}{l}64.1 \text { to } 79 \\
\text { (III) }\end{array}$ & Fair & $\begin{array}{l}\text { Water quality is usually } \\
\text { protected but occasionally } \\
\text { threatened or impaired }\end{array}$ & $\begin{array}{l}\text { Conditions sometimes depart } \\
\text { from natural or desirable } \\
\text { levels }\end{array}$ \\
\hline $\begin{array}{l}79.1 \text { to } 94 \\
\text { (II) }\end{array}$ & Good & $\begin{array}{l}\text { Water quality is protected } \\
\text { with only a minor degree of } \\
\text { threat or impairment }\end{array}$ & $\begin{array}{l}\text { Conditions rarely depart } \\
\text { from natural or desirable } \\
\text { levels }\end{array}$ \\
\hline $\begin{array}{l}94.1 \text { to } 100 \\
\text { (I) }\end{array}$ & Excellent & $\begin{array}{l}\text { Water quality is protected } \\
\text { with a virtual absence of } \\
\text { threat or impairment }\end{array}$ & $\begin{array}{l}\text { Conditions very close to } \\
\text { natural or pristine levels }\end{array}$ \\
\hline
\end{tabular}

Source: Terrado, 2010

The range of categories can be modified for every particular case of study. For calculation of CCMEWQI, the index incorporates three factors F1 (scope), F2 (frequency), and F3 (amplitude). 


\subsubsection{Determination of Factors F1, F2 and F3}

In order to compute the CCMEWQI, the factors F1, F2 and F3 have been explained as under:

\section{F1 (scope)}

The scope represents the percentage of variables that do not meet their objectives at least once during the time period under consideration (failed variables), in relation to the total number of variables measured. Accordingly,

$$
F 1=\left(\frac{\text { number of failed variables }}{\text { total number of variables }}\right) \times 100
$$

\section{F2 (frequency)}

Frequency represents the percentage of individual tests that do not meet objectives (failed tests). Accordingly,

$$
\mathrm{F} 2=\left(\frac{\text { number of failed tests }}{\text { total number of tests }}\right) \times 100
$$

\section{F3 (amplitude)}

Amplitude represents the amount by which failed test values do not meet their objectives. F3 is calculated in three steps:

\section{First Step}

The individual variable concentration may fall in any one of the following (a) or (b) condition.

(a) When the test value must not exceed the objective:

The number of times by which an individual concentration is greater than the objective (when the objective is maximum), the objective is termed as "excursion" and is expressed as follows:

$$
\text { excursion }_{i}=\left(\frac{\text { failed test value }_{\mathrm{i}}}{\text { objective }_{\mathrm{j}}}\right)-1
$$


(b) When the test value must not fall below the objective:

The number of times by which an individual concentration is less than the objective (when the objective is minimum), the objective is termed as "excursion" and is expressed as follows:

$$
\text { excursion }_{i}=\left(\frac{\text { objective }_{\mathrm{j}}}{\text { failed test value }_{\mathrm{i}}}\right)-1
$$

\section{Second Step}

The collective amount by which individual tests are out of compliance, is calculated by summing the excursions of individual tests from their objectives and dividing the total number of tests (both those are meeting objectives and those are not meeting the objectives). This variable, referred to as the normalized sum of excursions (nse), is calculated as:

$$
n s e=\frac{\sum_{i=1}^{n} \text { excursion }_{i}}{\text { total number of tests }}
$$

\section{Third Step}

F3 is then calculated by an asymptotic function that scales the normalized sum of excursions (nse) from objectives to yield a range between 0 and 100. Accordingly,

$$
\mathrm{F}_{3}=\left(\frac{\mathrm{nse}}{0.01 \mathrm{nse}+0.01}\right)
$$

\subsubsection{Determination of CCMEWQI using Factors F1, F2 and F3}

Once all the factors are obtained, the index can be calculated by summing the three factors as if they were vectors. The sum of the squares of each factor is, therefore, equal to the square of the index. This approach treats the index as a threedimensional space defined by each factor along one axis as shown in Figure 3.6. 
Hence, with this model, the index changes are in direct proportion to the changes in all three factors. Therefore, CCMEWQI can be computed with the following equation:

$$
C C M E W Q I=100-\left(\frac{\sqrt{\mathrm{F}_{1}^{2}+\mathrm{F}_{2}^{2}+\mathrm{F}_{3}^{2}}}{1.732}\right)
$$

Where, the divisor 1.732 normalizes the result to a range from 0 to 100 .

The specific variables, objectives, and time period used in calculating the index are not fixed and, indeed, could vary from region to region, depending on local conditions. It is, therefore, recommended that at a minimum of four variables having sampled at least four times should be used in the calculation. It is also expected that variables and objectives chosen can provide relevant information about a particular site (Terrado et al., 2010).

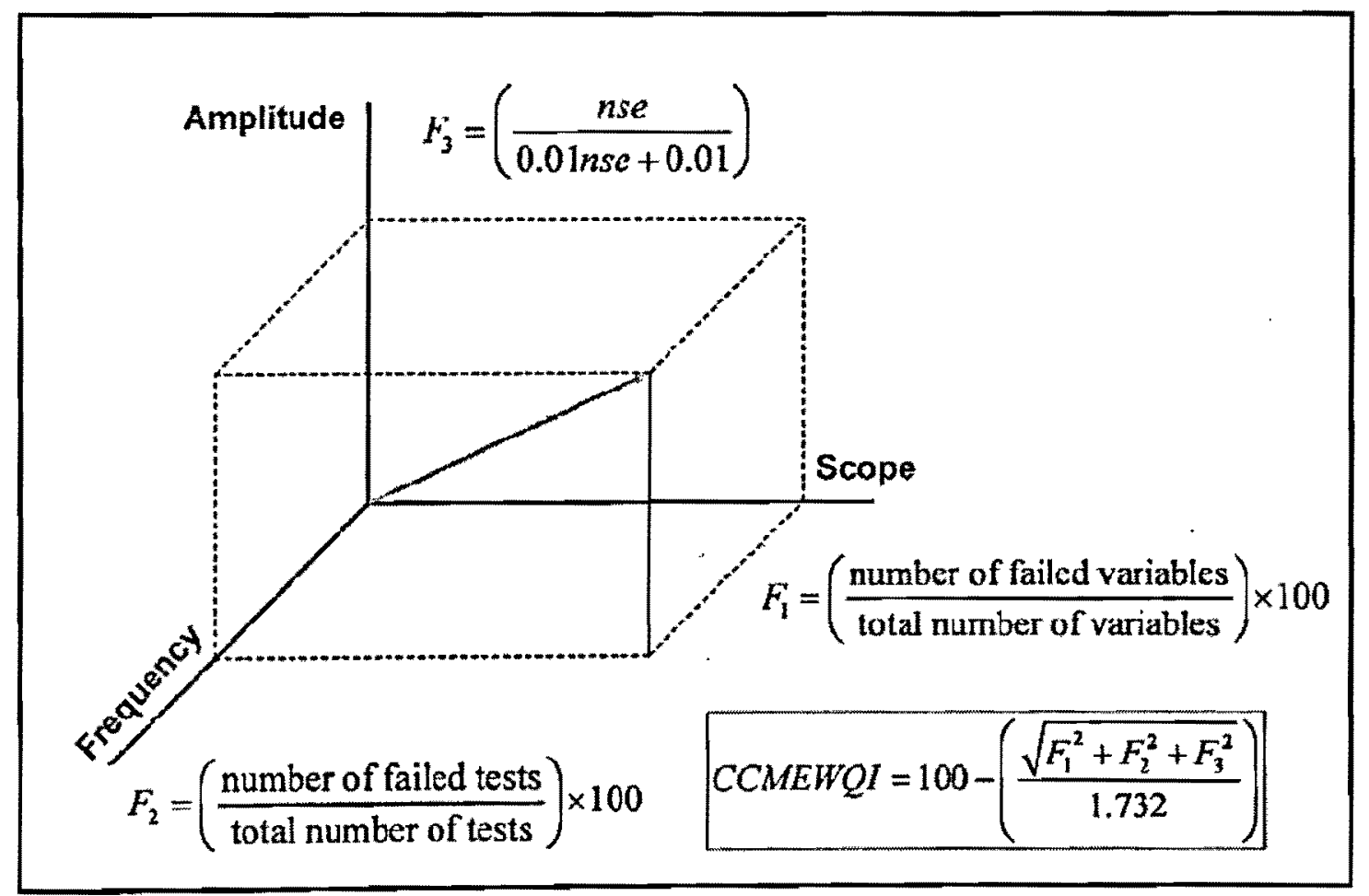

Figure 3.6 Graphical representation of the water-quality index (WQI) calculated in a three-dimensional space by summing three factors (F1, F2, and F3) as vectors Source: Terrado, 2010 


\subsubsection{Computation of QWQLI with Application of CCMEWQI System Approach}

The characteristic database simulated by QUAL2E as given in Table 3.4, is used to calculate the values of factors F1, F2 and F3. Four variables DO, BOD, T-N and T-P have been selected which are main contributors to the water quality. Thereafter, the maximum and minimum values of data distribution have been selected and established the desired quality objectives. The objectives should lie in between the maximum and minimum values of the variables. Selection of objectives differs depending on the end-use of the water. In case of Sapgyo River, maximum and minimum values of the variables and their respective desired objectives for calculating the water quality index are given in Table 3.10.

Table 3.10 Maximum and minimum values of variables with desired objectives

\begin{tabular}{|c|c|c|c|}
\hline 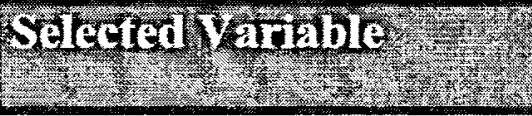 & $\begin{array}{l}\text { Nitiminim } \\
\text { value }\end{array}$ & $\begin{array}{l}\text { Naximum } \\
\text { Watur }\end{array}$ & $\begin{array}{l}\text { objectixe } \\
\text { staltex }\end{array}$ \\
\hline Dissolved oxygen (DO) & $5 \mathrm{mg} / \mathrm{L}$ & $15 \mathrm{mg} / \mathrm{L}$ & $\geq 6 \mathrm{mg} / \mathrm{L}$ \\
\hline $\begin{array}{l}\text { Biochemical oxygen demand } \\
\text { (BOD) }\end{array}$ & $3 \mathrm{mg} / \mathrm{L}$ & $5.75 \mathrm{mg} / \mathrm{L}$ & $\leq 4.2 \mathrm{mg} / \mathrm{L}$ \\
\hline Total nitrogen $(\mathrm{T}-\mathrm{N})$ & $2.8 \mathrm{mg} / \mathrm{L}$ & $5.5 \mathrm{mg} / \mathrm{L}$ & $\leq 4 \mathrm{mg} / \mathrm{L}$ \\
\hline Total phosphorous (T-P) & $0.07 \mathrm{mg} / \mathrm{L}$ & $0.37 \mathrm{mg} / \mathrm{L}$ & $\leq 0.3 \mathrm{mg} / \mathrm{L}$ \\
\hline
\end{tabular}

After calculating the values of factors F1, F2 and F3 by following the procedure as described in section 3.6.1, water quality index for Sapgyo River is calculated using Equation 3.11 for each element of the river channel as shown in Table 3.11. 
Table 3.11 Calculations of QWQLI using CCMEWQI system approach

\begin{tabular}{|c|c|c|c|c|c|c|c|c|c|c|c|c|c|c|c|c|c|c|}
\hline \multirow[b]{2}{*}{ 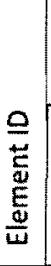 } & \multicolumn{4}{|c|}{$\begin{array}{c}\text { Test Results } \\
\text { Pass(0)/ } \\
\text { Fail(1) }\end{array}$} & \multicolumn{2}{|c|}{ Factor } & \multicolumn{2}{|c|}{$\begin{array}{l}\text { DO } \\
\text { (objective } \\
\geq 6 \mathrm{mg} / \mathrm{L} \text { ) }\end{array}$} & \multicolumn{2}{|c|}{$\begin{array}{l}\text { BOD } \\
\text { (objective } \\
\leq 4.2 \mathrm{mg} / \mathrm{L} \text { ) } \\
\end{array}$} & \multicolumn{2}{|c|}{\begin{tabular}{|l|}
$T-N$ \\
(objective \\
$\leq 4.0 \mathrm{mg} / \mathrm{l}$ ) \\
\end{tabular}} & \multicolumn{2}{|c|}{\begin{tabular}{|l|} 
T-P \\
(objective \\
$\leq 0.30 \mathrm{mg} / \mathrm{L}$ ) \\
\end{tabular}} & \multirow[b]{2}{*}{ nse } & \multirow[b]{2}{*}{$\begin{array}{l}\text { Factor } \\
\text { F3 }\end{array}$} & \multirow[b]{2}{*}{ awau } & \multirow[b]{2}{*}{$\begin{array}{l}\text { Class } \\
\text { (Category) }\end{array}$} \\
\hline & & : & $\underset{1}{z}$ & 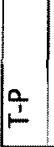 & F1 & $F 2$ & 总 & 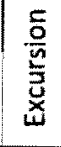 & 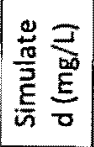 & 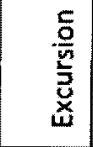 & 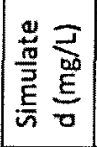 & 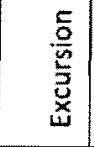 & 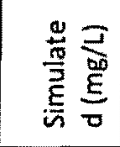 & 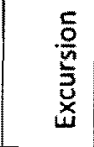 & & & & \\
\hline 1 & 0 & 1 & 0 & 0 & 25 & 25 & 11.15 & 0 & 5.75 & 0.369 & 2.565 & 0 & 0.098 & 0 & 0.092 & 8.45 & 79.01 & II (Good) \\
\hline 2 & 0 & 1 & 0 & 0 & 25 & 25 & 10.76 & 0 & 5.42 & 0.290 & 2.543 & 0 & 0.095 & 0 & 0.073 & 6.77 & 79.22 & II (Good) \\
\hline 3 & 0 & 1 & 0 & 0 & 25 & 25 & 10.58 & 0 & 5.10 & 0.214 & 2.521 & 0 & 0.091 & 0 & 0.054 & 5.08 & 79.38 & II (Good) \\
\hline 4 & 0 & 1 & 0 & 0 & 25 & 25 & 10.47 & 0 & 4.78 & 0.138 & 2.499 & 0 & 0.088 & 0 & 0.035 & 3.34 & 79.50 & II (Good) \\
\hline 5 & 0 & 1 & 0 & 0 & 25 & 25 & 10.39 & 0 & 4.50 & 0.071 & 2.479 & 0 & 0.086 & 0 & 0.018 & 1.75 & 79.56 & 11 (Good) \\
\hline 6 & 0 & 1 & 0 & 0 & 25 & 25 & 10.34 & 0 & 4.23 & 0.007 & 2.463 & 0 & 0.084 & 0 & 0.002 & 0.18 & 79.59 & II (Good) \\
\hline 7 & 0 & 1 & 1 & 1 & 75 & 75 & 10.77 & 0 & 4.81 & 0.145 & 7.108 & 0.777 & 0.353 & 0.177 & 0.275 & 21.55 & 37.51 & $V$ (Poor) \\
\hline 8 & 0 & 1 & 1 & 1 & 75 & 75 & 10.32 & 0 & 4.59 & 0.093 & 7.062 & 0.766 & 0.342 & 0.140 & 0.250 & 19.97 & 37.68 & V (Poor) \\
\hline 9 & 0 & 1 & 1 & 1 & 75 & 75 & 10.10 & 0 & 4.38 & 0.043 & 7.018 & 0.755 & 0.333 & 0.110 & 0.227 & 18.49 & 37.84 & $V$ (Poor) \\
\hline 10 & 0 & 1. & 1 & 1 & 75 & 75 & 10.34 & 0 & 4.49 & 0.069 & 7.586 & 0.897 & 0.367 & 0.223 & 0.297 & 22.91 & 37.35 & $V$ (Poor) \\
\hline 11 & 0 & 1 & 1 & 1 & 75 & 75 & 10.10 & 0 & 4.30 & 0.024 & 7.543 & 0.886 & 0.358 & 0.193 & 0.276 & 21.61 & 37.50 & $V$ (Poor) \\
\hline 12 & 0 & 0 & 1 & 1 & 50 & 50 & 9.97 & 0 & 4.12 & 0 & 7.500 & 0.875 & 0.350 & 0.167 & 0.260 & 20.66 & 57.47 & IV (Marginal) \\
\hline 13 & 0 & 0 & 1 & 1 & 50 & 50 & 9.90 & 0 & 3.96 & 0 & 7.482 & 0.871 & 0.347 & 0.157 & 0.257 & 20.43 & 57.50 & IV (Marginal) \\
\hline 14 & 0 & 0 & 1 & 1 & 50 & 50 & 9.87 & 0 & 3.80 & 0 & 7.442 & 0.861 & 0.341 & 0.137 & 0.249 & 19.95 & 57.58 & IV (Marginal) \\
\hline 15 & 0 & 0 & 1 & 1 & 50 & 50 & 9.86 & 0 & 3.64 & 0 & 7.402 & 0.851 & 0.336 & 0.120 & 0.243 & 19.53 & 57.65 & IV (Marginal) \\
\hline 16 & 0 & 0 & 1 & 1 & 50 & 50 & 9.85 & 0 & 3.48 & 0 & 7.364 & 0.841 & 0.331 & 0.103 & 0.236 & 19.10 & 57.71 & IV (Marginal) \\
\hline 17 & 0 & 0 & 1 & 1 & 50 & 50 & 9.86 & 0 & 3.34 & 0 & 7.326 & 0.832 & 0.326 & 0.087 & 0.230 & 18.67 & 57.78 & IV (Marginal) \\
\hline 18 & 0 & 0 & 1 & 1 & 50 & 50 & 9.87 & 0 & 3.20 & 0 & 7.290 & 0.823 & 0.322 & 0.073 & 0.224 & 18.30 & 57.83 & IV (Marginal) \\
\hline 19 & 0 & 0 & 1 & 1 & 50 & 50 & 9.88 & 0 & 3.06 & 0 & 7.255 & 0.814 & 0.319 & 0.063 & 0.219 & 17.98 & 57.87 & IV (Marginal) \\
\hline 20 & 0 & 0 & 1 & 으 & 25 & 25 & 10.36 & 0 & 2.81 & 0 & 8.272 & 1.068 & 0.270 & 0 & 0.267 & 21.07 & 76.24 & III (Fair) \\
\hline 21 & 0 & 0 & 1 & 0 & 25 & 25 & 10.20 & 0 & 2.80 & 0 & 8.176 & 1.044 & 0.265 & 0 & 0.261 & 20.70 & 76.35 & 1111 (Fair) \\
\hline 22 & 0 & 0 & 1 & 0 & 25 & 25 & 10.14 & 0 & 2,79 & 0 & 8.086 & 1.022 & 0.261 & 0 & 0.255 & 20.34 & 76.45 & III (Fair) \\
\hline 23 & 0 & 0 & 1 & 0 & 25 & 25 & 10.12 & 0 & 2.79 & 0 & 8.001 & 1.000 & 0.258 & 0 & 0.250 & 20.00 & 76.55 & 111 (Fair) \\
\hline 24 & 0 & 0 & 1 & 0 & 25 & 25 & 10.11 & 0 & 2.78 & 0 & 7.920 & 0.980 & 0.255 & 0 & 0.245 & 19.68 & 76.64 & 111 (Fair) \\
\hline 25 & 0 & 0 & 1 & 0 & 25 & 25 & 10.63 & 0 & 2.84 & 0 & 7.928 & 0.982 & 0.241 & 0 & 0.246 & 19.71 & 76.63 & III (Fair) \\
\hline 26 & 0 & 0 & 1 & 0 & 25 & 25 & 10.77 & 0 & 3.03 & 0 & 7.994 & 0.999 & 0.247 & 0 & 0.250 & 19.98 & 76.55 & III (Fair) \\
\hline 27 & 0 & 0 & 1 & 0 & 25 & 25 & 11.02 & 0 & 2.96 & 0 & 7.961 & 0.990 & 0.236 & 0 & 0.248 & 19.84 & 76.59 & III (Fair) \\
\hline 28 & 0 & 0 & 1 & 0 & 25 & 25 & 11.10 & 0 & 3.15 & 0 & 8.029 & 1.007 & 0.244 & 0 & 0.252 & 20.12 & 76.51 & III (Fair) \\
\hline 29 & 0 & 0 & 1 & 0 & 25 & 25 & 11.18 & 0 & 2.85 & 0 & 7.545 & 0.886 & 0.218 & 0 & 0.222 & 18.14 & 77.06 & III (Fair) \\
\hline 30 & 0 & 0 & 1 & 0 & 25 & 25 & 11.14 & 0 & 2.95 & 0 & 7.612 & 0.903 & 0.219 & 0 & 0.226 & 18.42 & 76.98 & 111 (Fair) \\
\hline 31 & 0 & 0 & 1 & 0 & 25 & 25 & 11.10 & 0 & 3.04 & 0 & 7.680 & 0.920 & 0.221 & 0 & 0.230 & 18.70 & 76.91 & III (Fair) \\
\hline
\end{tabular}




\subsection{Result Analysis}

Viewing the QWQLI indexing result of NSFWQI system approach, the following analysis can be made:

(i) The simulation results from element 1 to element 6 have been graded as "Class II". Accordingly, the upper reaches of the main channel has been categorized having a "Low" level of pollutant loading. The simulation results of the remaining reaches have been graded as "Class III" which categorized the reaches having pollutant loadings of "Medium" level.

(ii) Element 6 has the lowest pollutant load (79.4, Class II) amongst all elements, whereas element 10 has the highest pollutant load (54.5, Class III) amongst all elements of the river.

(iii) The overall pollutant loads of the main channel may be considered acceptable, as there is no element whose QWQLI is lower than 50. However, T-N of the main channel should be improved, because T-Ns of most elements have been graded as "Class IV" which indicates a "High" loading level.

Similarly, viewing the QWQLI indexing result using CCMEWQI system approach, the following analysis can be made:

(i) The simulation results from element 1 to 6 have been graded as "Class II". Accordingly, the upper reaches of the main channel have been rated in "Good" category. This means that the elements have low level of pollutant loadings which is same as analyzed in case of NSFWQI system. The simulation results from elements 7 to 11 have been graded as "Class $\mathrm{V}$ (Poor)" which shows that they have high level of pollutant loadings. This is because of discharging the pollutant loadings through the point sources located at the elements 7 and 10 . Moreover, the water quality is poorest at element 10 showing water quality index level 37.35 as lowest in the channel. 
(ii) As analyzed in case of NSFWQI system, the element 6 has the lowest pollutant load with maximum water quality index level 79.59 amongst all elements. The simulation results from element 12 to 19 have been graded as "IV (Marginal)" and from elements 20 to 31 have been graded as "III (Fair)".

(iii) The overall pollutant load of the main channel may not be considered acceptable because of the poor water quality level from element 7 to 11 , which is below 50 of water quality index level. The factor results of T-N and T-P shows that elements 7 to 11 need quality improvements of their pollutant loadings.

A comparison of the two results, obtained by using the NSFWQI and CCMEWQI systems approaches, has been presented for each element in Figure 3.7. In case of NSFWQI, all results have been considered acceptable using 50 as the minimum water quality level. However, in case, we raise the minimum water quality level to 60 , the elements 7 to 18 need quality improvement of their pollutant loadings.

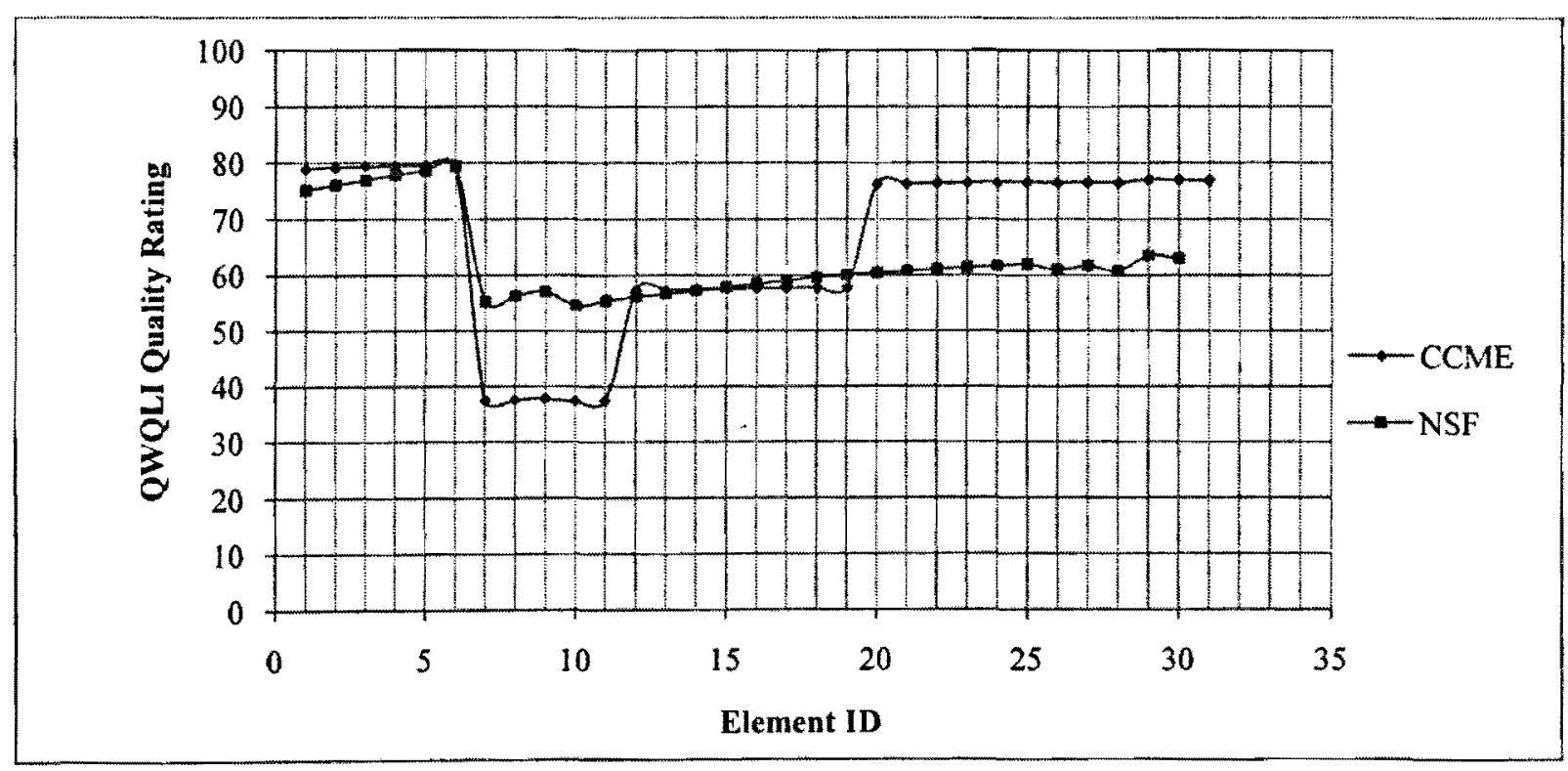

Figure 3.7 Comparison of QWQLI results using NSFWQI and CCMEWQI systems approaches 
In case of CCMEWQI with 50 as the minimum water quality level, the elements 7 to 11 are needed to be improved. If we further raise the minimum water quality level to 60 , then elements 7 to 19 are required to be improved.

The above analysis shows that the use of CCMEWQI system approach provides better improvement of the elements, resulting in a better water quality of the channel. Moreover, a comparison of NSFWQI and CCMEWQI systems on the basis of different criteria is provided in Table 3.12 which also shows that the CCMEWQI system is better than NSFWQI system (Terrado et al., 2010).

Table 3.12 Comparison of NSFWQI and CCMEWQI based on different criteria

\begin{tabular}{|l|l|l|l|}
\hline S. N. & Criteria & NSFWQI & CCMEWQI \\
\hline 1 & Parameters measured using continuous sampling & Bad & Good \\
\hline 2 & Adaptability to different uses of water body & Bad & Good \\
\hline 3 & Existing guidelines to define objectives & Good & Fair \\
\hline 4 & Experience of real applications & Fair & Good \\
\hline 5 & $\begin{array}{l}\text { Consideration of the amplitude } \\
\text { (amount by which the objectives are not met) }\end{array}$ & Fair & Good \\
\hline 6 & Programming difficulty & Fair & Good \\
\hline 7 & Tolerance to missing data & Bad & Fair \\
\hline 8 & Need of synchronized data & Bad & Good \\
\hline 9 & Tolerance to wrong data & Bad & Bad \\
\hline
\end{tabular}

Note: S.N. is denoted for Serial Numbers.

Source: Terrado, 2010 


\section{CHAPTER 4}

\section{DISCUSSION AND FINDINGS}

\subsection{Finding of Better QWQLI Result}

The QUAL2E model is used to simulate the pollutant loadings received after treatment through WTPs prior to discharge them into the river. The QUAL2E model divides the whole river channel into equal elements to treat them as controlled channels. The quality of the constituent loadings of these elements is required to be maintained at the desired river water quality level. For this purpose, the results of two water quality index systems have been compared to select the better one. In this study, NSFWQI and CCMEWQI systems approaches have been used to compute the water quality indices for the same pollutant data simulated by QUAL2E model.

In case of NSFWQI system, the main component is the selection of variables that mainly contribute to the water quality. While using this system approach, it has been observed that the element having lowest water quality should be improved first. Further the system has indicated a particular variable which is required to be improved in that element. For example, Table 3.8 shows that starting from headwater, element 7 is the first poor in water quality and its variable $\mathrm{T}-\mathrm{N}$ having quality level 43.1 is required to be treated first to improve the water quality level. The weight assignment is an important task that

finally differentiates the water quality of all the elements and therefore, it assigns the water quality index level to each element.

In case of CCMEWQI system, it is important to note that the scope factor F1 which shows the percentage of failed variables, is the most significant factor in calculating the index. For this reason, it is important to carefully observe those variables that despite generally fulfilling the quality objectives are failed to meet the desired objectives at various occasions. In this study, the values of F1 and F2 are same for all elements because only one simulation result of QUAL2E is accounted for to calculate the F2 value. However, increased number of simulation tests may give different values of F2. Hence, to get more accurate and realistic results, it is recommended that at a minimum of four 
variables having sampled at least four times should be used in the calculation (Terrado, 2010).

The values of F3 depend on the values of established objectives. Over estimation of the index occurs when using the variables whose relevance is doubtful and their objectives are difficult to exceed. This may be in case of temperature and water level. For this reason, these variables are not included in this process. From the data aggregation point of view, if the individual data aggregation level is higher, the quality index level is better. The results of NSFWQI has shown that the elements from 7 to 11 have the index rating as $55.3,56.3,57.1,54.6$, and 55.4 respectively, whereas the result of CCMEWQI have shown that these elements have their rating as $37.51,37.68,37.84,37.34$, and 37.50 respectively. This means that the CCMEWQI has rated these elements at lesser level than that of NSFWQI. Accordingly, use of CCME results need more improvement level to maintain the desired river water quality. Furthermore, Table 3.12 also shows that CCMEWQI has better usefulness than NSFWQI with consideration of the same criteria.

The above discussion concludes that computation of QUAL2E water quality loading index with application of CCMEWQI system approach provides better control on the water quality. In other words, it can be concluded that maintaining the water quality at the end-use is on safer side by using the CCMEWQI system approach. Therefore, this study has proved that CCMEWQI is the better option to keep the water quality of the channel on safer side.

However many advantages, CCMEWQI has some disadvantages. One of the disadvantages is that this index assigns equal importance to particular variables. During the process of calculation, all variables are given the same weight without any distinction among their potential environmental impact. So this aspect should be improved as much as possible. Moreover, the variables used in calculating the indices are probably described only a limited description of the factors influencing categorization of the water body. Hence, the index score represents a partial diagnostic of the water quality that can be easily biased. It is, therefore, important to take into account that the attained diagnostic of water quality will be valid for a particular set of parameters only, and that using different parameters will probably lead to different results. 
To sum up the discussion, it may be concluded that despite having some disadvantages, CCMEWQI is proved to be a useful and better system in comparison to NSFWQI to determine the QUAL2E water quality loading index for the Sapgyo River. Finally, the QWQLI results obtained by using CCMEWQI are found better to maintain the river water quality especially for meeting the desired quality objectives on safer side at the end-use.

\subsection{Decision-Making Process Based on Better Found QWQLI Result}

QUAL2E water quality loading index has a great importance for the decision makers. The QWQLI indexing can provide a simple description of the pollutant loads simulated by QUAL2E model. It can be used to decide whether or not the pollutant loading scenario of an element should be improved based on the improvement requirements by decision makers. However, an appropriate decision-making process regarding pollutant loads must involve detailed solutions of how to mitigate the pollutant loads of "unsatisfactory" elements. Therefore, a decision-making process using pollutant loadings simulated by QUAL2E model supported by a single water quality rating value of QWQLI is designed in this section to make improvement actions for the pollutant loads. It should be kept in mind that QWQLI is a single water quality rating value for each element of the river channel. In this study, the decision-making process is based on the better found QWQLI results obtained by application of CCMEWQI system approach. As shown in Fig. 4.1, the process is a modeling judgment procedure repeated on each element until all of the elements meet the desired improvement requirements. The decision process is divided into two parts:

(i) "Where to improve"

(ii) "How to improve"

\section{First Decision - Where to Improve?}

After the initial water quality modeling, some elements may be considered as candidates to be improved on the basis of QWQLI indexing. However, the problem arises for determining the element which has the first priority for improvement. For this purpose, 
locate the poorest element that is required to be improved first. Accordingly, the first decision involves the following steps:

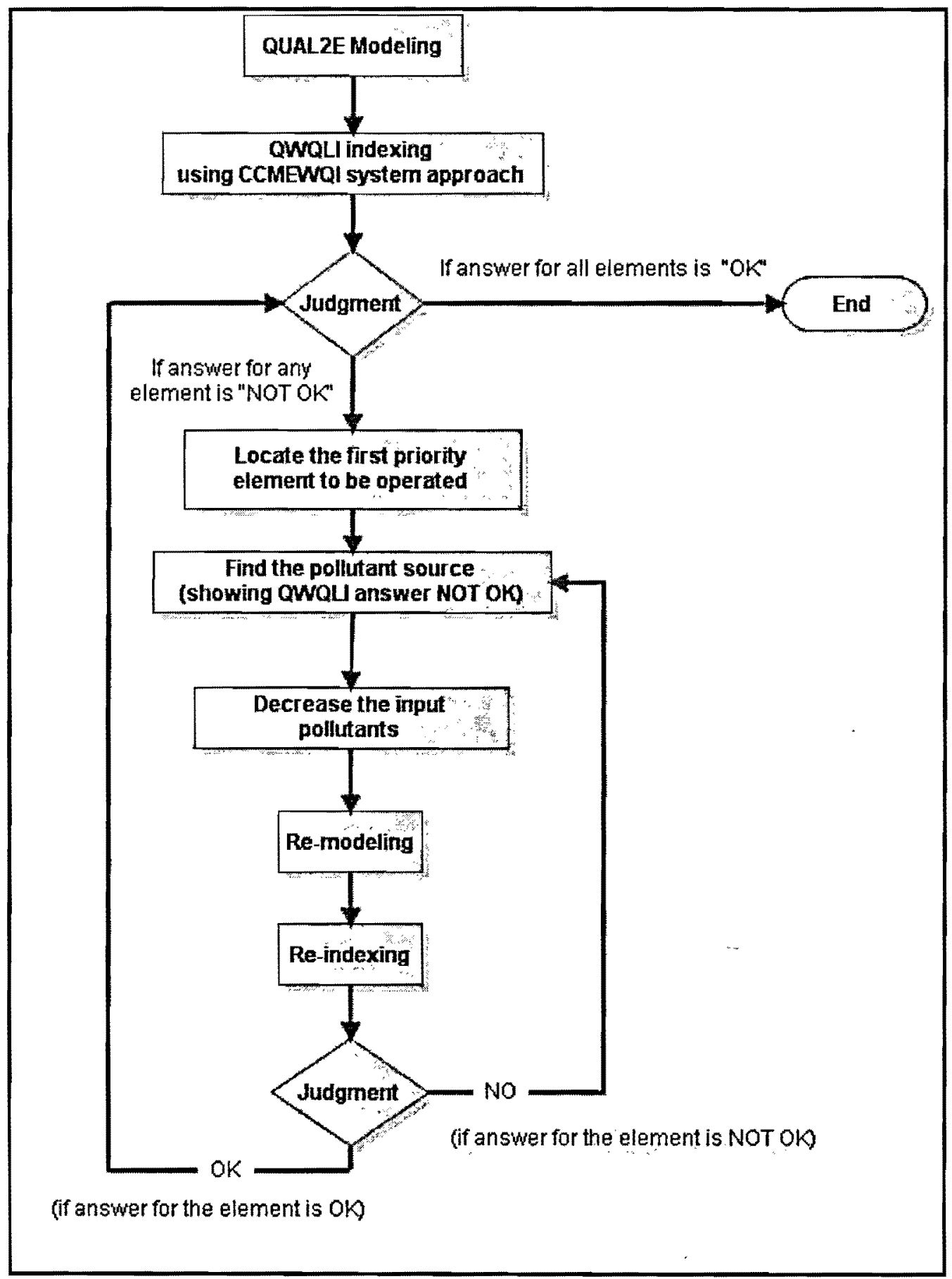

Figure 4.1 Decision-making process based on better found QWQLI result 


\section{First Step}

First of all, perform the QUAL2E modeling to simulate the pollutant loadings after treating them through WTPs. This is an initial modeling process which is described in Section 3.2. After improvement of the first operating element, the improvement result is the origin of the next improvement.

\section{Second Step}

Compute the QWQLI indexing using CCMEWQI system approach to find a single value water quality index for each element of the river channel.

\section{Third Step}

Make a judgment of the indexing result. If all elements are "OK", which implies "no element needs to be improved" based on the improvement requirements, the process reaches the end. Otherwise, the process turns to the next step.

\section{Fourth Step}

If some elements need improvement, then first define the uppermost candidate element as the operating element. This is because of the fact that water pollutants always flow with water from upper reaches to lower reaches. It is obvious that the uppermost candidate element has the highest priority of improvement.

\section{Fifth Step}

After deciding the uppermost candidate for improvement, the process moves to the second decision.

\section{Second Decision - How to Improve?}

The second decision is a continuation of the first decision when there is an element to be improved. Through the design of improvement actions, the element can be changed to meet the improvement requirements of desired objectives. This involves the following steps: 


\section{First Step}

Find the pollutant source of the operating element. All of the headwater and input elements are candidates of this source. Owing to the natural flow direction of water, the sources should be found from the upstream reaches of the element. If more than one source is found, only one source will be selected for a reduction in load. The source should have the greatest impact on the operating element. It is clear that the amount of input pollutants and the flow distance to the element are two major factors. However, because decreases of input pollutants in this study are implemented from upper sources to lower sources, a source that has been improved for its nearer downstream elements can unquestionably meet the improvement requirements of its elements that are farther downstream. Therefore, it is assumed that only the source nearest to the operating element is selected.

\section{Second Step}

Decrease the amount of input pollutants BOD, T-N, and T-P of the pollutant source. The decrease will mitigate the pollutant loads of the downstream elements.

\section{Third Step}

Re-model the river by QUAL2E for each attempt to decrease the level of input pollutants.

\section{Fourth Step}

Re-modeling results will be indexed with the QWQLI rating using CCMEWQI system approach.

\section{Fifth Step}

Check the answer of the operating element. If the answer is "OK", the process proceeds to "sixth step". Otherwise, the process returns to "second step".

\section{Sixth Step}

In case, the operating element is "OK", the improvement of the element is finished. The procedure will then switch to the first decision to determine the next operating element. 
During this process, decreasing input pollutants is the most important step. Therefore, it is important to design the improvement actions in a feasible and efficient manner.

\subsection{Analyzing Decision-Making Process Based on QWQLI Result of Sapgyo River}

In this study, the improvement objectives have been assumed as follows:

(i) For any element, the DO, BOD, T-N, and T-P should meet the conditions of desired objectives as laid down in Table 3.10.

(ii) After improvement, the QWQLI value of any element should be greater than 79 (Class II) to be graded in "Good" quality.

Based on these improvement goals, the river reaches from element 7 become the candidate elements to be improved, as they have "unsatisfactory" QWQLIs of T-N and T-P. By the process of the first decision, element 7 is defined as the first operating element, as it is the uppermost candidate element. As shown in Table 3.3, the pollutant source of element 7 is "Point Source 1", which discharges to the Sapgyo River at element 7. By the process of the second decision, the input pollutants from "Point Source 1" are decreased until element 7 is found to be satisfactory. Repeating the process for each candidate element, the pollutant loads of the entire main channel of the Sapgyo River are improved, as shown in Table 4.1. A comparison of QWQLI results of Sapgyo River, obtained before and after improvement has been illustrated in Figure 4.2

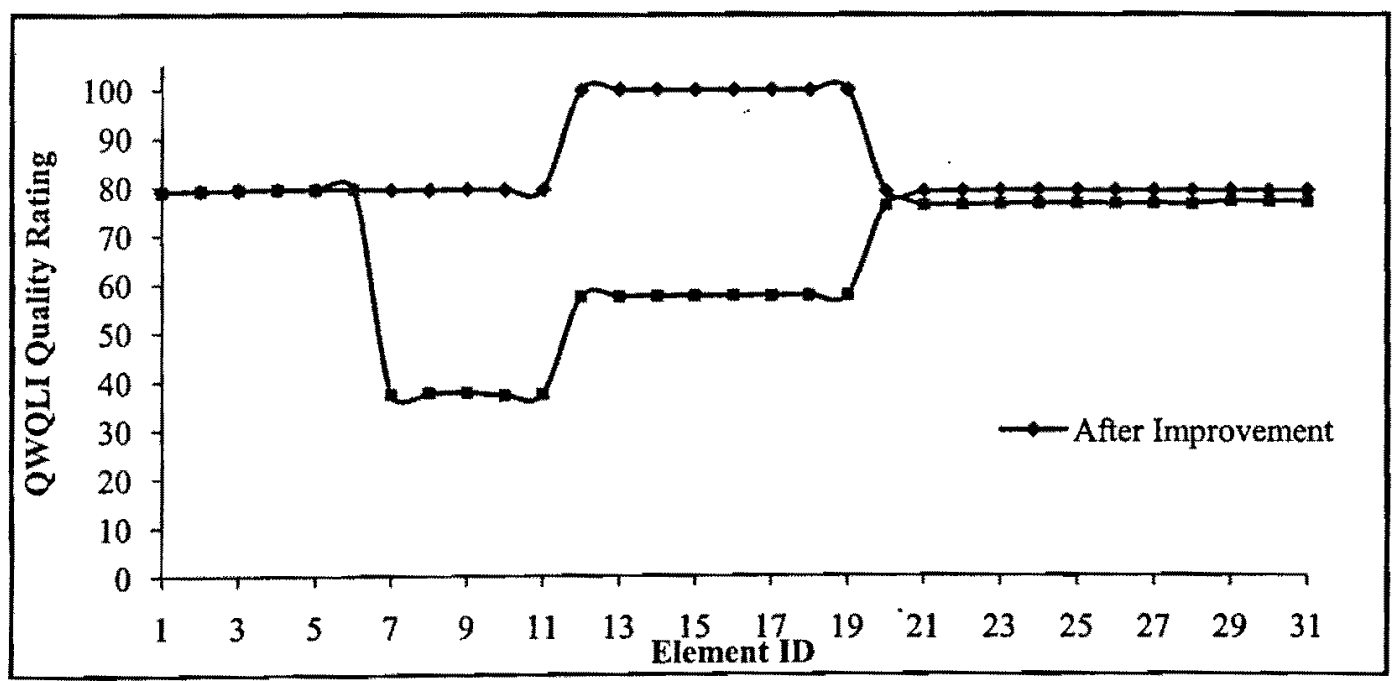

Figure 4.2 Comparison of QWQLI results of Sapgyo River obtained before and after improvement 
Table 4.1 Decision-making result of Sapgyo River using CCMEWQI system approach

\begin{tabular}{|c|c|c|c|c|c|c|c|c|c|c|c|c|c|c|c|c|c|c|}
\hline \multirow[b]{2}{*}{ 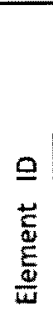 } & \multicolumn{4}{|c|}{$\begin{array}{c}\text { Test Results } \\
\text { Pass(0)/ } \\
\text { Faill(1) }\end{array}$} & \multicolumn{2}{|c|}{ Factor } & \multicolumn{2}{|c|}{$\begin{array}{l}\text { Do } \\
\text { (objective } \\
26 \mathrm{mg} / \mathrm{L} \text { ) } \\
\end{array}$} & \multicolumn{2}{|c|}{$\begin{array}{l}\text { BOD } \\
\text { (objective } \\
\leq 4.2 \mathrm{mg} / \mathrm{L} \text { ) }\end{array}$} & \multicolumn{2}{|c|}{$\begin{array}{l}T-N \\
\text { (objective } \\
\leq 4.0 \mathrm{mg} / \mathrm{L} \text { ) } \\
\end{array}$} & \multicolumn{2}{|c|}{$\begin{array}{l}\text { T-P } \\
\text { (objective } \\
\leq 0.30 \\
\mathrm{mg} / \mathrm{L} \text { ) } \\
\end{array}$} & \multirow[b]{2}{*}{ nse } & \multirow[b]{2}{*}{\begin{tabular}{|l|} 
Facto \\
$\mathrm{r} F 3$
\end{tabular}} & \multirow[b]{2}{*}{ owau } & \multirow[b]{2}{*}{$\begin{array}{l}\text { Class } \\
\text { (Category) }\end{array}$} \\
\hline & & 8 & $\underset{1}{z}$ & i & F1 & $F 2$ & 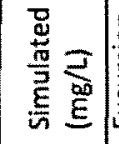 & 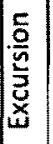 & 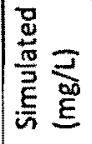 & $\frac{5}{\frac{5}{n}}$ & 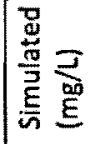 & 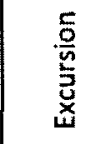 & 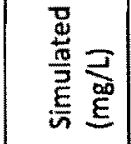 & 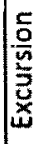 & & & & \\
\hline 1 & 0 & 1 & 0 & 0 & 25 & 25 & 11.15 & 0 & 5.75 & 0.369 & 2.565 & 0 & 0.098 & 0 & 0.098 & 8.45 & 79.01 & II (Good) \\
\hline 2 & 0 & 1 & 0 & 0 & 25 & 25 & 10.76 & 0 & 5.42 & 0.290 & 2.543 & 0 & 0.095 & 0 & 0.095 & 6.77 & 79.22 & II (Good) \\
\hline 3 & 0 & 1 & 0 & 0 & 25 & 25 & 10.58 & 0 & 5.10 & 0.214 & 2.521 & 0 & 0.091 & 0 & 0.091 & 5.08 & 79.38 & $\|$ (Good) \\
\hline 4 & 0 & 1 & 0 & 0 & 25 & 25 & 10.47 & 0 & 4.78 & 0.138 & 2.499 & 0 & 0.088 & 0 & 0.088 & 3.34 & 79.50 & II (Good) \\
\hline 5 & 0 & 1 & 0 & 0 & 25 & 25 & 10.39 & 0 & 4.50 & 0.071 & 2.479 & 0 & 0.086 & 0 & 0.086 & 1.75 & 79.56 & $\|$ (Good) \\
\hline 6 & 0 & 1 & 0 & 0 & 25 & 25 & 10.34 & 0 & 4.23 & 0.007 & 2.461 & 0 & 0.084 & 0 & 0.084 & 0.18 & 79.59 & II (Good) \\
\hline 7 & 0 & 1 & 0 & 0 & 25 & 25 & 10.77 & 0 & 4.81 & 0.145 & 3.677 & 0 & 0.207 & 0 & 0.207 & 3.50 & 79.49 & II (Good) \\
\hline 8 & 0 & 1 & 0 & 0 & 25 & 25 & 10.32 & 0 & 4.59 & 0.093 & 3.631 & 0 & 0.196 & 0 & 0.196 & 2.27 & 79.55 & $\|$ (Good) \\
\hline 9 & 0 & 1 & 0 & 0 & 25 & 25 & 10.10 & 0 & 4.38 & 0.043 & 3.588 & 0 & 0.187 & 0 & 0.187 & 1.06 & 79.58 & II (Good) \\
\hline 10 & 0 & 1 & 0 & 0 & 25 & 25 & 10.34 & 0 & 4.49 & 0.069 & 3.838 & 0 & 0.210 & 0 & 0.210 & 170 & 79.56 & (S) (Gond) \\
\hline 11 & 0 & 1 & 0 & 0 & 25 & 25 & 10.10 & 0 & 4.30 & 0.024 & 3.794 & 0 & 0.201 & 0 & 0.201 & 0.55 & 79.58 & IGodt \\
\hline 12 & 0 & 0 & 0 & $\underline{0}$ & 0 & 0 & 9.97 & 0 & 4.12 & 0.369 & 3.752 & 0 & 0.193 & 0 & 0.193 & 0.00 & 100.00 & \\
\hline 13 & 0 & 0 & 0 & 0 & 0 & 0 & 9.90 & 0 & 3.96 & 0.290 & 3.739 & 0 & 0.191 & 0 & 0.191 & 0.00 & 100.00 & ent) \\
\hline 14 & 0 & 0 & 0 & 0 & 0 & 0 & 9.87 & 0 & 3.80 & 0.214 & 3.699 & 0 & 0.184 & 0 & 0.184 & 0.00 & 100.00 & cellent) \\
\hline 15 & 0 & 0 & 0 & 0 & 0 & 0 & 9.86 & 0 & 3.64 & 0 & 3.659 & 0 & 0.179 & 0 & 0.179 & 0.00 & 100.00 & cellent) \\
\hline 16 & 0 & 0 & 0 & 0 & 0 & 0 & 9.85 & 0 & 3.48 & 0 & 3.621 & 0 & 0.174 & 0 & 0.174 & 0.00 & 100.00 & (Excellent) \\
\hline 17 & 0 & 0 & 0 & 0 & 0 & 0 & 9.86 & 0 & 3.34 & 0 & 3.583 & 0 & 0.169 & 0 & 0.169 & 0.00 & 100.00 & 1 (Excellent) \\
\hline 18 & 0 & 0 & 0 & 0 & 0 & 0 & 9.87 & 0 & 3.20 & 0 & 3.546 & 0 & 0.166 & 0 & 0.166 & 0.00 & 100.00 & I (Excellent) \\
\hline 19 & 0 & 0 & 0 & 0 & 0 & 0 & 9.88 & 0 & 3.06 & 0 & 3.514 & 0 & 0.162 & 0 & 0.162 & 0.00 & 100.00 & I (Excellent) \\
\hline 20 & 0 & 0 & 1 & 0 & 25 & 25 & 10.36 & 0 & 2.81 & 0 & 5.382 & 0 & 0.176 & 0 & 0.176 & 7.95 & 79.08 & 11 (Good) \\
\hline 21 & 0 & 0 & 1 & 0 & 25 & 25 & 10.20 & 0 & 2.80 & 0 & 5.287 & 0.346 & 0.171 & 0 & 0.171 & 7.14 & 79.14 & $\|$ (Good) \\
\hline 22 & 0 & 0 & 1 & 0 & 25 & 25 & 10.14 & 0 & 2.79 & 0 & 5.197 & 0.322 & 0.167 & 0 & 0.167 & 6.96 & 79.20 & 11 (Good) \\
\hline 23 & 0 & 0 & 1 & 0 & 25 & 25 & 10.12 & 0 & 2.79 & 0 & 5.111 & 0.299 & 0.164 & 0 & 0.164 & 6.49 & 79.25 & $\|$ (Good) \\
\hline 24 & 0 & 0 & 1 & 0 & 25 & 25 & 10.11 & 0 & 2.78 & 0 & 5.031 & 0.278 & 0.161 & $\underline{0}$ & 0.161 & 6.05 & 79.29 & II (Good) \\
\hline 25 & 0 & 0 & 1 & 0 & 25 & 25 & 10.63 & 0 & 2.84 & 0 & 5.196 & 0.258 & 0.164 & 0 & 0.164 & 6.96 & 79.20 & II (Good) \\
\hline 26 & 0 & 0 & 1 & 0 & 25 & 25 & 10.77 & 0 & 3.03 & 0 & 5.204 & 0.299 & 0.170 & 0 & 0.170 & 7.00 & 79.19 & II (Good) \\
\hline 27 & 0 & 0 & 1 & 0 & 25 & 25 & 11.02 & 0 & 2.91 & 0 & 5.159 & 0.301 & 0.161 & 0 & 0.161 & 6.75 & 79.22 & $\|$ (Good) \\
\hline 28 & 0 & 0 & 1 & 0 & 25 & 25 & 11.10 & 0 & 3.09 & 0 & 5.228 & 0.290 & 0.169 & 0 & 0.169 & 7.13 & 79.18 & II (Good) \\
\hline 29 & 0 & 0 & 1 & 0 & 25 & 25 & 11.18 & 0 & 2.81 & 0 & 5.187 & 0.307 & 0.155 & 0 & 0.155 & 6.91 & 79.20 & $\|$ (Good) \\
\hline 30 & 0 & 0 & 1 & 0 & 25 & 25 & 11.14 & 0 & 2.90 & 0 & 5.254 & 0.297 & 0.156 & 0 & 0.156 & 7.27 & 79.16 & $\|$ (Good) \\
\hline 31 & 0 & 0 & 1 & 18 & 25 & 25 & 11.10 & 0 & 2.99 & 0 & 5.322 & 0.314 & 0.157 & & 0.157 & 7.63 & 79.12 & $\|$ (Good) \\
\hline
\end{tabular}


According to the decision-making result, BODs of most elements do not have to improve, as the improvement goal is almost satisfied. In contrast, the T-Ns and T-Ps of the river reaches starting from element 7 are largely improved, as shown in Fig. 4.3 and 4.4. The river reaches from element 7 to element 19 show larger improvements than other elements. This goal has been achieved in a diverse manner by decreasing the amounts of input pollutants from pollutant sources. These decreases are quantified by the concentration unit. However, if converted to a mass unit, like $\mathrm{kg}$ /day (kilogram per day), the decreases can reflect the reduced quantities of input pollutants more directly. The relationship of these two units can be written as given in the following equation 4.1 (Song, 2008):

$$
\mathrm{P}_{\mathrm{m}}=86.4 \mathrm{QP}_{\mathrm{c}}
$$

Where, $\quad \mathrm{P}_{\mathrm{m}}=$ amount of pollutants in $\mathrm{kg} /$ day

$\mathrm{Q}=$ source flow rate in $\mathrm{m}^{3} / \mathrm{s}$

$P_{c}=$ amount of pollutants in $\mathrm{mg} / \mathrm{L}$

Therefore, with the help of equation (4.1), the decision makers can readily determine as how many BOD, T-N, and T-P of the elements should be decreased for each pollutant source.

Besides many advantages of QWQLI computed with application of CCMEWQI system approach, some disadvantages are also exists. In this study, a drawback of this index was observed while QWQLI results were simulated after decreasing the pollutant loads. According to these results as shown in Table 4.1, the elements from 12 to 19 achieved QWQLI as 100 which is not realistic. The main reason is that the four pollutants have been used only once in the calculation of factors F1, F2 and F3 and all DO values have already met the desired objective. It is, therefore, recommended that at a minimum of four variables having sampled at least four times should be used in the calculation to get more accurate and realistic results. 


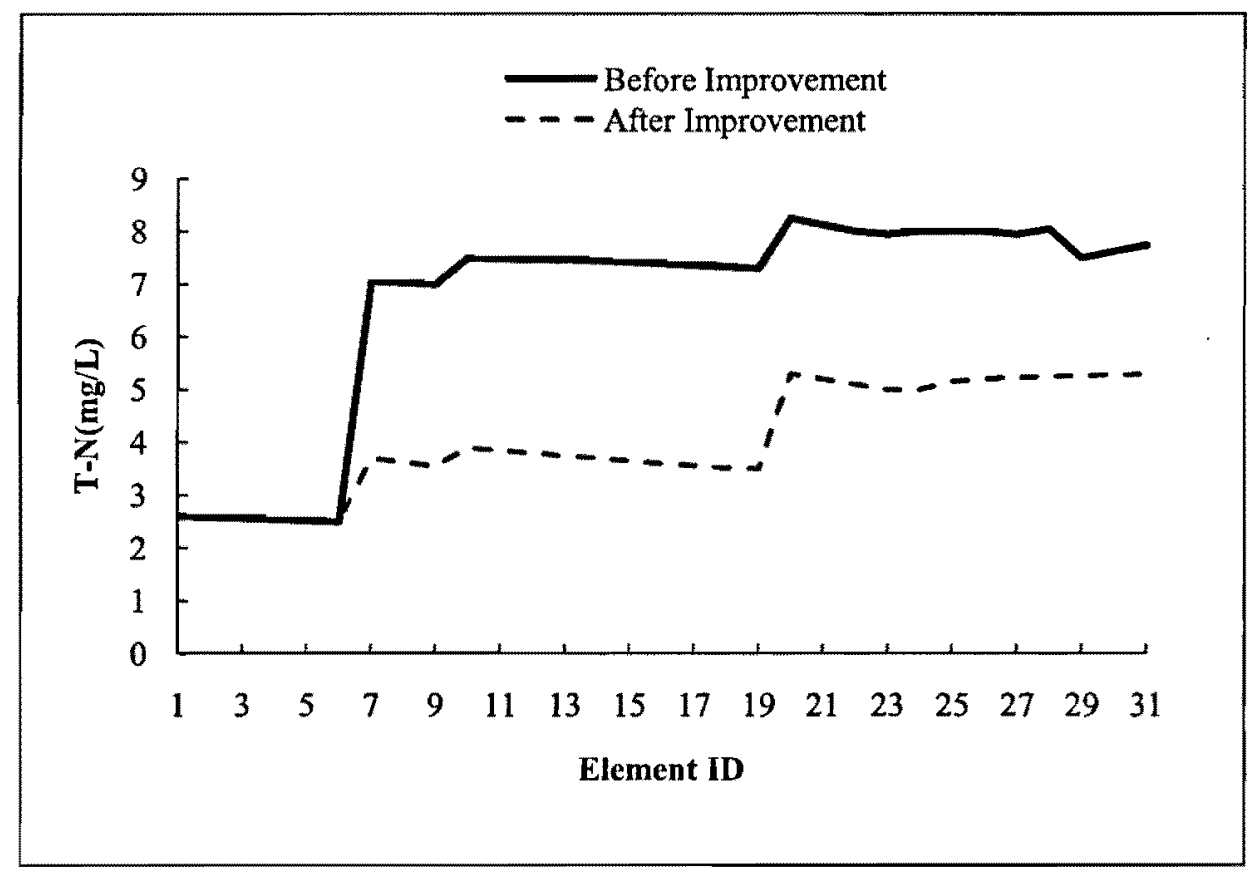

Figure 4.3 Comparison of simulated concentration of $\mathrm{T}-\mathrm{N}$ before and after improvement

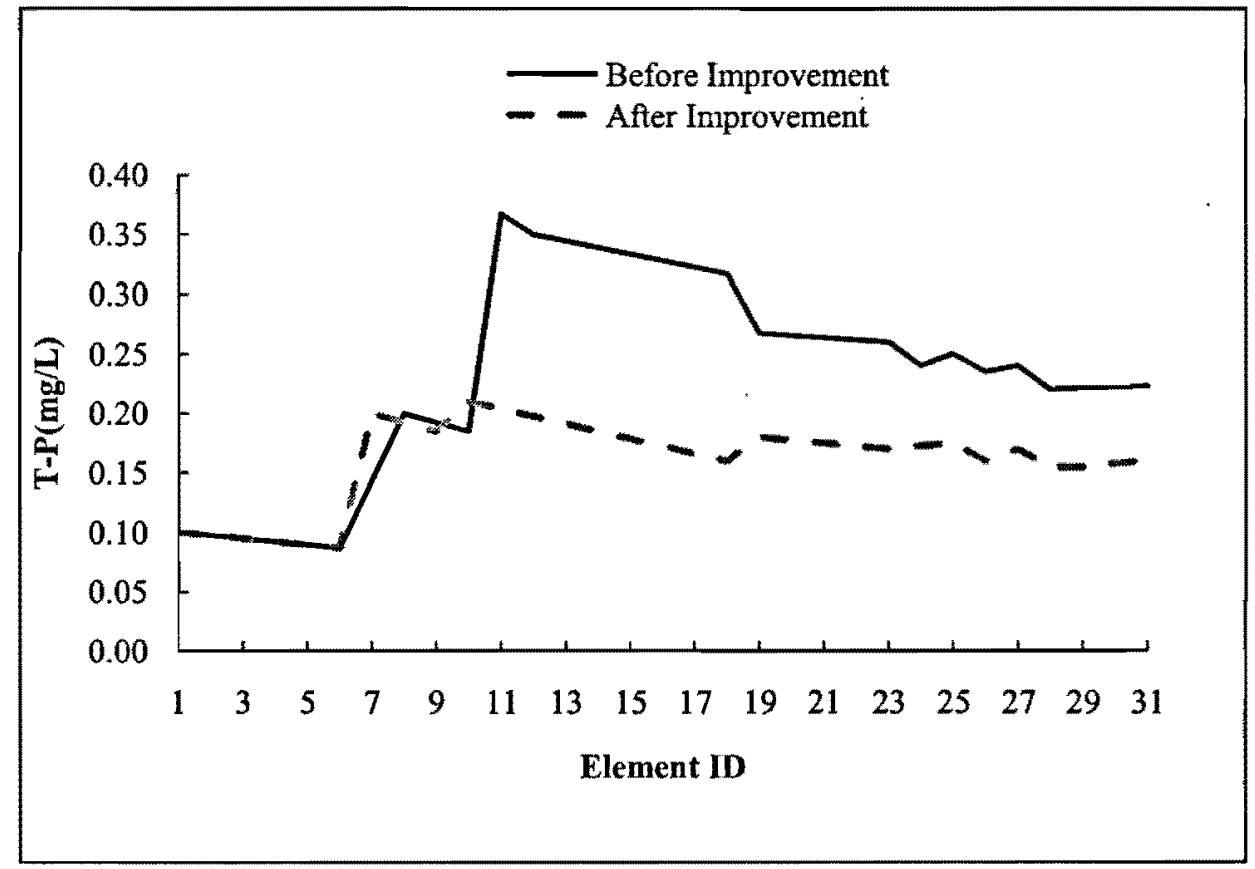

Figure 4.4 Comparison of simulated concentration of T-P before and after improvement 


\section{CHAPTER 5}

\section{CONCLUSIONS}

The QUAL2E model is a worldwide popular steady-state model for the evaluation of surface water quality of rivers and streams. This model is a strong tool with a consistent mathematical formulation despite its simplifying assumptions. The adequacy of generated curves to the observed data is a strong proof of model consistency.

The calibration and validation of QUAL2E model was made using field measurements of the Sapgyo River and the results were validated on the two selected monitoring stations located at element numbers 23 (SR1) and 29 (SR2) along the river. The validation of the calibrated parameters with the observed data indicated that good correlation was maintained between the calculated and observed variables. This has supported the reliability of the parameters. The model was used to simulate the pollutant loadings received after treatment through WTPs, prior to discharge them into the river. On the basis of the simulated results, a decision analysis was performed.

The decision analysis of water quality is an important branch of a multi-criteria decision analysis. To enhance the sustainability of water-quality-management system, there is a need to translate the modeling results of simulated pollutants into an understandable single unit which is termed as "water quality index (WQI)" to help the decision-makers for making relevant judgments. The respective decisions are used for water quality improvement.

Under this study, water quality index was determined using QUAL2E model with application of two different system approaches of NSFWQI and CCMEWQI. For this purpose, the simulation results of QUAL2E modeling were translated into a water quality index which was termed as "QUAL2E water quality loading index (QWQLI)" to describe the river water quality rating in a single unit for use of the decision-makers and general public audience. 
In order to find the better result out of the two different water quality loading index systems (NSFWQI and Canadian water quality index CCMEWQI), the same pollutant data set of Sapgyo River simulated by QUAL2E model was used. The results of QWQLI using NSFWQI system approach has shown that the elements from 7 to 11 have the index rating as $55.3,56.3,57.1,54.6$, and 55.4 respectively, whereas the result of QWQLI using CCMEWQI system approach have shown that these elements have their rating as $37.51,37.68,37.84,37.34$, and 37.50 respectively. It has proved that use of CCME result needs more improvement in water quality level to maintain the desired river water quality objectives.

A comparison presented by Terrado et al. (2010) also shows that CCMEWQI system has better usefulness than NSFWQI system with consideration of the same criteria. Therefore, QWQLI result computed with application of Canadian water quality index system is proved to be a better system for summarizing and transmitting information to decision-makers.

Using the better found QWQLI, a recurrent modeling-judgment decision-making process for pollutant loads was proposed. Although this QWQLI could not readily reflect the accurate water quality, it has evaluated and classified the simulation results yielded by QUAL2E in a better way. This index is very effective to locate the elements whose pollutant loads should be decreased in the decision-making process.

The output of proposed decision-making process shows that QWQLI has the ability to describe and classify the modeling result by QUAL2E and to help decision makers to design their improvement actions on pollutant loads. Unlike other WQIs that are limited to the monitored water quality, QWQLI is a specific index for water quality that is not popular but has great importance as it can be simulated by modeling of pollutant loads. It can translate the complex and obscure water quality modeling result to a simple and easily understandable description to help the water quality managers.

However, besides many advantages of QWQLI computed by applying the Canadian water quality index system approach, there also exists some disadvantages. A 
drawback of this index was observed while QWQLI results were simulated after decreasing the pollutant loads. The result shows that the elements from 12 to 19 have achieved quality rating as 100 which are not realistic.

Therefore, further study should be carried out to include the automatic procedure of locating the elements to be improved and deciding the decreasing sizes of input pollutants by using, at a minimum, four variables having simulated samples at least four times to be used in computation of QWQLI with application of CCMEWQI system approach. 


\section{REFERENCES}

Ambrose, R.B., Wool, T.A., Martin, J.L., 1993. WASP5.x, A Hydrodynamic and Water Quality Model - Model Theory, User's Manual, and Programmer's Guide. Published by USEPA, USA.

Anh, D.T., Bonnet, M.P., Vachaud, G., Minh, C.V., Prieur, N., Duc, L.V., Anh, L.L., 2006. Biochemical modeling of the Nhue River (Hanoi, Vietnam): practical identifiability analysis and parameter estimation. Journal of Ecological Modelling, Volume 193, Issues 3-4, Pages 182-204.

Boyacioglu, H., 2007. Development of a water quality index based on a European classification scheme. Journal of Water SA, Volume 33, Issue 1, Pages 101-106.

Brown, L.C., Barnwell, T.O., 1987. The enhanced stream water quality models QUAL2E and QUAL2E-UNCAS: documentation and user manual, EPA/600/3-87/007. Published by United States Environmental Agency, Athens, GA, USA.

Brown, R.M., McClelland, N.I., Deininger, R.A., Tozer, R.G., 1970. A water quality index - do we dare? Journal of Water Sewage Works, Volume 117, Issue 10, Pages 339343.

CCME, 2001. Canadian Water Quality Guidelines for the Protection of Aquatic Life, CCME Canada. Published by Environment Canada.

Chapra, S.C., 2008. Surface water quality modeling. Published by Waveland Press, Inc., Long Grove, Illinois, USA.

Chaudhury, R.R., Sobrinho, J.A.H., Wright, R.M., Sreenivas, M., 1998. Dissolved oxygen modeling of the Blackstone River (northeastern United States). Journal of Water Research, Volume 32, Issue 8, Pages 2400-2412.

Ciravolo, L., Indelicato, S., Viviani, G., 2000. Stream water quality models: an application to the Simeto River basin. Published by Measurements and Modelling in Environmental Pollution, Pages 53-62.

Cole, T., Buchak, E., 1995. CE-QUAL-W2: A Two-dimensional, Laterally Averaged, Hydrodynamic and Water Quality Model, Version 2.0. Published by Army Engineer Waterways Experiment Station, Vicksburg, MS, USA.

Cox, B.A., 2003. A review of currently available in-stream water-quality models and their applicability for simulating dissolved oxygen in lowland rivers. Journal of Science of The Total Environment, Volumes 314-316 (Pages 1-917), Pages 335-377.

Cude, C.G., 2002. Oregon water quality index: a tool for evaluating water quality management. Joumal of the American Water Resources Association, Volume 38, Issue 1, Pages 315-318.

Drolc A., Koncan J.Z., 1996. Water quality modelling of the river Sava, Slovenia. Journal of Water Research, Volume 30, Issue 11, Page 2587-2592. 
Finnegan, C.J., van Egmond, R.A., Price, O.R., Whelan, M.J., 2009. Continuous-flow laboratory simulation of stream water quality changes downstream of an untreated wastewater discharge. Journal of Water Research, Volume 43, Issue 7, Pages 1993-2001.

Ghosh, N.C., Mcbean, E.A., 1998. Water quality modelling of the Kali river, India. Journal of Water, Air and Soil Pollution, Volume 102, Issues 1-2, Pages 91-103.

Henze, M., Grady Jr, C.P.L., Gujer, W., Marais, G.V.R., T. Matsuo, 1987, Activated Sludge Model No. 1. Published by IAWQ (formerly IAWPRC), Scientific and Technical Reports No. 1, London, UK.

Horton, R.K., 1965. An index-number system for rating water quality. Journal of Water Pollution Control Federation, Volume 37, Issue 3, Pages 300-306.

Huang, G.H., Xia, J., 2001. Barriers to sustainable water-quality management. Journal of Environmental Management, Volume 61, Issue 1, Pages 1-23.

Iowa Watershed Monitoring and Assessment Program, 2006. Why a Water Quality Index? Published by Department of Natural Resources, Iowa, USA, http://publications.iowa.gov/5353/.

James, A., 1984. An Introduction to Water Quality Modelling. Published by Wiley, Chichester, UK.

Liu, W., Chen, D., 2009. Spatial impact of organic matters from point sources on stream water quality. Journal of Mining Science and Technology (China), Volume 19, Issue 2, Pages 256-261.

Malczewski, J., 1999. GIS and Multicriteria Decision Analysis. Published by John Wiley \& Sons, USA.

Ning, S.K., Chang, N.-B., Yang, L., Chen, H.W., Hsu, H.Y., 2001. Assessing pollution prevention program by Qual2e simulation analysis for the Kao-Ping River basin, Taiwan. Journal of Environmental Management, Volume 61, Issue 1, Pages 61-76.

Orden, G.N.V., Uchrin, C.G., 1993. The study of dissolved oxygen dynamics in the Whippany river, New Jersey using the QUAL2E model. Journal of Ecological Modelling, Volume 70, Issues 1-2, Pages 1-17.

Ott, W.R., 1978. Environmental Indices: Theory and Practice. Published by Ann Arbor Science Publishers, USA.

Palmieri, V., Jose de Carvalho, R., 2006. Qual2e model for the Corumbatai River. Journal of Ecological Modelling, Volume 198, Issues 1-2, Pages 269-275.

Park, S.S., Lee, Y.S., 2002. A water quality modeling study of the Nakdong River, Korea. Journal of Ecological Modelling, Volume 152, Issue 1, Pages 65-75.

Prati, L., Pavanello, R., Pesarin, F., 1971. Assessment of surface water quality by a single index of pollution. Journal of Water Research, Volume 5, Issue 9, Pages 741-751. 
Rauch, W., Henze, M., Koncsos, L., Reichert, P., Shanahan, P., Somlyody, L., Vanrolleghem, P., 1998. River water quality modelling: I. State of the art. Journal of Water Science and Technology, Volume 38, Issue 11, Pages 237-244.

Said, A., Stevens, D.K., Sehlke, G., 2004. An Innovative Index for Evaluating Water Quality in Streams. Journal of Environmental Management, Volume 34, Issue 3, Pages 406-414.

Song, T., 2008. GIS-based Decision-making Process for Water Quality Management using Water Quality Index. Doctor dissertation. Published by Geoinformatic Engineering, Inha University, Korea.

Song, T., Kim K., 2009. Development of a water quality loading index based on water quality modeling. Journal of Environmental Management, Volume 90, Issue 3, Pages 1534-1543.

Streeter, H.W., Phelps, E.B., 1925. A Study of Pollution and Natural Purification of the Ohio, published in Public Health Bulletin, Volume 146, Page 175.

Terrado, M., Barcelo, D., Tauler, R., Borrell, E., Sergio de Campos, Barcelo, D., 2010. Surface-water-quality indices for the analysis of data generated by automated sampling networks. Journal of Trends in Analytical Chemistry, Volume 29, Issue 1, Pages 40-52.

USACE, 1986. HEC-5 Simulation of Flood Control and Conservation Systems, Appendix on Water Quality Analysis. Published by USACE Hydrolic Center, USA.

Viessman, W.J., Hammer, M.J., Perez, E.M., Chadik, P.A., 2009. Water Supply and Pollution Control, Eighth Edition. Published by Pearson Prentice Hall, Upper Saddle River, NJ 07458, USA. 